Die letzten Tage waren ausgefüllt mit letzten Vorbereitungen für die Haager Schlußkonferenz. Es wird ein schwerer Gang werden. Ich werde mitgehen. Der Reichskanzler wünscht es und namentlich Minister Curtius, der in der letzten Kabinettssitzung sagte, ich sei ganz unentbehrlich. Wenn er heute mal nachsehen wolle, was auf der ersten Haager Konferenz passiert sei, schlage er immer im „Pünder" nach, womit er den Band meiner täglichen damaligen Telegramme meinte ${ }^{109}$.

Morgen, am 1. 1. 1930, großer Neujahrsempfang bei Herrn Reichspräsidenten von Hindenburg. Muß schon vormittags den Frack anziehen. Nachher wollen wir zwei zu Frau Stresemann gehen. Am 2. 1. haben wir vormittags noch eine wichtige Kabinettssitzung über die Haager Schlußkonferenz, den Nachtragshaushalt 29 und den Haupthaushalt 30. Am Abend geht's dann ab nach dem Haag.

\title{
Mittwoch, den 1. Januar 1930
}

Viel Neues hat der heutige Festtag nicht gebracht. Heute früh gleich in den Frack geworfen, dann zum Hochamt nach Lichterfelde. Nachher bei der Mutter ein neues Jahr gewünscht und von dort per Auto mit Magda in die Stadt. Um 12.30 Uhr große Gratulationskur beim Reichspräsidenten in der üblichen Form: der Reichskanzler, die Reichsminister und die Staatssekretäre. Die beiden Reden zwischen Reichspräsident und Reichskanzler, von Herrn Meißner und mir vorbereitet, gingen glatt vonstatten. Dann der übliche Händedruck an alle, auch an mich mit besonderer Herzlichkeit. Ungefähr vor mir stehend sagte der alte Herr am Schluß: „Nun, meine Herren, mit Gott vorwärts! Ein altes Wort, das ich gern gebrauche, auch den Meinen gegenüber in schweren Tagen. So darf ich es auch hier gebrauchen, vor Ihnen, meinen ersten Mitarbeitern. Und nun lassen Sie sich's gut gehen. Guten Morgen, meine Herren! “

Mit dem Reichskanzler zurück zur Reichskanzlei, der auch mir und meiner Familie frohes neues Jahr wünschte. Nachher mit meiner Frau Besuch gemacht bei Frau Stresemann, die aber verreist war. Heute abend packte ich noch, da es morgen ab nach dem Haag geht. Ich fahre diesmal mit recht bedrücktem Gefühl. Ein schwerer Gang!

\section{Sonntag, den 19. Januar 1930}

Diese Zeilen schreibe ich im Haag Sonntagabend, in meinem behaglichen Zimmer im Hotel Zentral. Inzwischen habe ich seit dem 3. Januar als Delegationsmitglied der Haager Konferenz viel erlebt. Meine Erlebnisse spiegeln sich wider im wesentlichen in meinen vierundzwanzig Telegrammen, die ich täglich nach Berlin an Reichsregierung und Reichspräsidenten gerichtet habe. Dort mag man alles nach-

109 Die für die Berliner Regierungsstellen bestimmten Telegramme Pünders von der Ersten Haager Konferenz (6.-31. August 1929) sind in den Akten der Reichskanzlei erhalten (Bundesarchiv Koblenz). 
lesen ${ }^{110}$. Ich fühle persönlich eine recht starke innere Befriedigung, einerseits über das Konferenzergebnis, andererseits aber auch deswegen, weil ich glaube, hier nicht überflüssig gewesen $\mathrm{zu}$ sein und rechtschaffen mitgearbeitet zu haben. Besonders mein Verhältnis zum diesmaligen Delegationsführer Curtius hat sich sehr harmonisch gestaltet, wie früher mit dem jetzt leider toten Stresemann. An ihn habe ich oft denken müssen.

Auch sonst brachte das Leben hier viel Abwechslung. Schrecklich viele Einladungen, darunter auch bei der Königin; hier ein natürlich sehr interessanter, aber in seiner Aufmachung doch recht bescheidener Empfang. Mehrere Male beim Grafen und Gräfin Zech ${ }^{\mathbf{1 1 1}}$, dem liebenswürdigen deutschen Gesandtenpaar, dann bei der Stadt, das unvergeßliche Frühstück bei den Franzosen und unsere Wiedereinladung, der Presseempfang, Frühstück beim Italiener, unsere Einladung für Bundeskanzler Schober ${ }^{112}$ usw. Außerordentlich hat es mich interessiert, den neuen französischen Ministerpräsidenten Tardieu näher kennen zu lernen, ohne Zweifel der Mann der Zukunft in Frankreich, und sonst all die Großen der Erde, die hier versammelt waren. Mehrere Empfänge auch beim holländischen Außenminister van Beelarts. Herrliches Wetter, wie im Frühling.

Morgen ist die Schlußsitzung der Konferenz. Heute abend müssen wir die letzten Vorbereitungen dafür treffen. Dann ist aber Schluß. Am Dienstag dann wieder der übliche Zauber in Berlin. Wir müssen dort schnell arbeiten, damit die Ratifizierung der Young-Gesetze bald erfolgen kann. Moldenhauer war eine glänzende Nummer hier auf der Konferenz ${ }^{\mathbf{1 1 3}}$. Ich bin stolz, an seiner Wahl so schuldig gewesen zu sein.

\section{Donnerstag, den 13. Februar 1930}

Fast ein Monat seit der letzten Aufzeichnung. Schade! Aber nach meiner Rückkehr war schrecklich viel los. Ich kam zum geliebten Tagebuch kaum. Und wenn ich erst den "Dreh" verloren habe, finde ich wieder schwer den Anschluß. Ich kenne mich! Eigentlich nur um dem entgegenzutreten, schreibe ich heute diese wenigen Zeilen, damit erst mal wieder etwas da steht. Also: Diese ersten Wochen standen im Zeichen des Young-Planes. Gerade heute haben wir die mehrtägige Debatte der ersten Lesung beendet. Ab morgen Ausschüsse, vermutlich ab Mittwoch nächster Woche zweite Lesung. Soweit sieht alles ganz gut aus. Aber, aber! Das Zentrum verlangt - und wohl nicht ganz zu Unrecht -, daß zuvor noch Klar-

110 Auch diese - mehr als 24 - Telegramme (3.-20. Januar 1930) sind samt einigen Aktenvermerken und Telefonaten als „Handakten" in der Registratur der Reichskanzlei besonders gesammelt worden (= Bd 303/305). Zum Ablauf der Haager Schlußkonferenz siehe J. Curtius, a. a. O. (vgl. Anm. 5), S. 121 ff. und L. Zimmermann, Deutsche Außenpolitik, S. $386 \mathrm{ff}$.

111 Dr. Julius Graf von Zech-Burkersroda, geb. 1885, Berufsdiplomat, seit 1928 Gesandter in Den Haag.

112 Dr. Johann Schober, geb. 1874, österreichischer Politiker, keiner Partei zugehörig, sich aber als Repräsentant der nationalen Gruppen in Österreich fühlend, langjähriger Polizeipräsident von Wien, 1929 Bundeskanzler.

$113 \mathrm{Vgl}$. auch die Hervorhebung der Tätigkeit Moldenhauers durch J. Curtius, a. a. O. (vgl. Anm. 5), S. 124 und 126. 
heit über die Finanzlage geschaffen werden müsse. Deshalb verhandeln wir jetzt täglich über Finanzfragen und garnicht mehr über den Young-Plan. Wir haben trotz der Reparationsnachlässe ein Minus von 700 Millionen im Etat 1930. Davon entfallen 250 Millionen auf die Arbeitslosenversicherung. Gerade heute abend hatten wir Kabinettssitzung über die Fragen. $\mathrm{Ob}$ wir uns in den nächsten Tagen einigen, ist sehr zweifelhaft.

$\mathrm{Zu}$ Hause ist alles wohl und munter. In Preußen haben sie mittlerweile den tüchtigen Kultusminister Becker ${ }^{114}$ abgesägt und ihn durch den Sozialdemokraten Grimme ersetzt. Unglaublich! Ein Schlag für den Parlamentarismus. Abends sind wir fast immer auf Gesellschaft, mal nett, mal langweilig, insgesamt reichlich anstrengend, aber doch insgesamt eine interessante Pflicht.

\section{Mittwoch, den 26. Februar 1930}

Ich bin noch nicht wieder richtig im Zug hinsichtlich des Tagebuchs! Es kommt aber auch hinzu, daß ich in diesen Wochen fast jeden Abend mit Magda eingeladen bin und infolgedessen zu nichts anderem abends komme. Im übrigen hat sich noch nicht viel ereignet. Politisch stehen wir immer noch in den Verhandlungen mit dem „neuen Plan“ und den Finanzfragen. Morgen werden wir uns im Kabinett mit den neuen Deckungsvorschlägen Moldenhauers gefassen. Seine Renommee hat schon etwas gelitten. Ich sehe nicht sehr ruhig in die Zukunft.

Das letzte Wochenende stand unter dem Zeichen des Besuchs des Bundeskanzlers Schober aus Wien. Sehr ordentlich verlaufen. Ein prächtiger Mann. Gestern abend war ich hinter einem anderen Diner beim General von Schleicher eingeladen, wo auch der Kronprinz Wilhelm ${ }^{\mathbf{1 1 5}}$ anwesend war. Ein ungemein reizvoller Abend. Ich habe mich völlig offen fast drei Stunden mit dem hohen Herrn unterhalten. Hinterher hat er unserem Gastgeber gesagt, für ihn wäre das Erlebnis des Abends das Kennenlernen des Staatssekretärs Pünder gewesen und er würde es sehr begrüßen, mich bald mal wiederzusehen!

\section{Montag, den 3. März 1930}

Über Nacht ist schwere Krise ausgebrochen! Am vergangenen Sonnabend hat der Herr Reichspräsident Herrn Dr. Scholz ${ }^{116}$ von der Deutschen Volkspartei empfangen: ohne jeden Erfolg. Die Volkspartei weigert sich, ein Notopfer oder etwas

114 Dr. Carl Heinrich Becker, geb. 1876, Professor an der Universität Berlin; 1919-1921 und 1922-1925 Staatssekretär im preußischen Kultusministerium, 1921 und 1925-1930 preuBischer Kultusminister. Vgl. auch die Würdigung seines Lebens durch E. Wende: C. H. Becker, Mensch und Politiker, Stuttgart 1959.

115 Wilhelm, Kronprinz des Deutschen Reiches und von Preußen, geb. 1882, lebte nach seiner Rückkehr aus dem niederländischen Exil (1923) auf seinen Besitzungen in Öls (Schlesien) oder auf Schloß Cecilienhof bei Potsdam.

116 Dr. Ernst Scholz, geb. 1874, Jurist und Kommunalpolitiker, 1913-1920 Oberbürgermeister von Charlottenburg, 1920/21 Reichswirtschaftsminister, seit 1921 Mitglied des Reichstages (DVP), 1929 Vorsitzender der Deutschen Volkspartei. 
Ähnliches in irgend einer Weise und Höhe mitzumachen. Dadurch Finanzgesetze im Augenblick unmöglich. Und was wird aus den Young-Gesetzen am nächsten Donnerstag? Heute Montag früh hatten wir Kabinettssitzung. Man erwartete eigentlich allgemein den Rücktritt der Regierung, aber es zeigten sich doch noch gewisse Lösungsmöglichkeiten und daher Vertagung und Fortsetzung morgen nachmittag. Minister Curtius liegt mit fiebriger Grippe im Bett. Präsident Schacht hat dem Herrn Reichspräsidenten ganz vertraulich seinen Rücktritt angekündigt ${ }^{117}$.

Sonntag, den 9. März 1930

Wir leben augenblicklich in einer so scheußlichen Krise, wie ich sie in den Jahren meiner jetzigen Stellung überhaupt noch nicht erlebt habe. Das Kabinett hat nach vieler Arbeit und vielem Hin und Her sich einstimmig auf ein großes Finanzprogramm geeinigt. Alle Regierungsparteien sind auch mehr oder weniger bereit, auf diesen Boden zu treten, bis auf die Volkspartei, die ausgerechnet ihren eigenen Finanzminister Moldenhauer damit völlig desavouiert. Der Hort des Widerstandes ist hier Dr. Scholz, der, nach langer Krankheit genesen, versucht, sich seine Partei und Fraktion wieder völlig in die Hand zu spielen. Und nun stehen wir da; das Zentrum und die Bayern verlangen nicht ohne einen gewissen Grund der Berechtigung, daß vor Annahme des Youngplanes Klarheit über die Kassensanierung eintreten soll. In den Ausschüssen hat sich das Zentrum schon dieserhalb der Stimme enthalten. Gestern am Sonnabend hatten die Fraktionsführer Besprechung, die nach eingehender Durchsprache der verschiedenen Steuervorschläge der Regierung ohne Ergebnis verliefen 118. Darauf heute am Sonntag nachmittag Fortsetzung im Reichstag. Die Sitzung ist bald zu Ende, da eine Änderung in der Haltung der Fraktionen nicht eingetreten ist, $d . h$. sie verlief auch ohne Ergebnis. Was soll nun werden? Morgen ist Schluß der zweiten Lesung. Mühsam ist eine Einigung erzielt, daß die Abstimmung der zweiten Lesung erst am Dienstag stattfinden soll und die Schlußabstimmung der dritten Lesung am Mittwoch. $\mathrm{Da} \beta$ eine Änderung bis dahin eintreten wird, erscheint sehr unwahrscheinlich. Die Finanzspezialisten der Weimarer Koalition bereiten einen Kompromi $\beta$ vor. $\mathrm{Ob}$ etwas dabei herauskommt, glaube ich kaum. Außerdem wäre eine reine Weimarer Koalition ein recht unfreundliches und unerfreuliches Gebilde. Mein Plan ist ein anderer, den ich auch bereits mit Dr. Brüning und Meißner besprochen habe. Das Zentrum muß das Junktim vor der zweiten oder jedenfalls vor der dritten Lesung fallen lassen, und zwar auf einen Appell des Reichspräsidenten hin. Ein solcher Empfang soll Diens-

117 H. Schacht, a. a. O. (vgl. Anm. 28), S. $326 \mathrm{ff}$.

118 In einer Niederschrift über die Parteiführexbesprechung vom 8. März 1930 heißt es: „Für die Zentrums-Fraktion erklärte der Abg. Brüning, daß seine Partei nach wie vor daran festhalte, dem Neuen Reparationsplan nur dann zustimmen zu können, wenn die Voraussetzungen für die Sanierung der Kassenlage exfüllt seien . . . Der Abg. Leicht erklärte, daß das Schicksal des Finanzprogramms die Haltung seiner Fraktion zu den Gesetzen des Haager Schlußprotokolls sehr wesentlich beeinflusse." Akten Reichskanzlei, Bd 1021. 
tag vormittag stattfinden. Über den Empfang soll ein Communiqué herausgegeben werden, auf das sich das Zentrum beziehen kann. Dann Zustimmung zum YoungPlan und sofort hinterher Verhandlung über die Finanzfragen auf Grund der dann aus dem Reichsrat gekommenen Vorlagen. Wenn dann keine Einigung zu erzielen ist, Auflösung des Reichstags, und in der Zwischenzeit bis zum Zusammentritt positive Erledigung der Deckungsvorlagen einschließlich des Etats 30 auf Grund von Artikel 4.8. Wenn dann der neue Reichstag kommt, mag er den Etat und die anderen Finanzgesetze außer Kraft setzen, nachdem die Rheinland-Räumung in Gang gekommen ist! Morgen werde ich mit Herrn Meißner und Herrn Brüning alles weitere besprechen.

Inzwischen hat Herr Präsident Schacht seinen Abschied genommen. Recht unbequem im Augenblick, aber - wie ich immer sage - Schacht ist schon seit langer Zeit ein toter Mann. Er hat überall abgewirtschaftet. Nachfolger wird wahrscheinlich mein verehrter alter Gönner, Reichskanzler a. D. Luther. Ich habe wacker daran mitgearbeitet.

Gestern abend bei Staatssekretär Weismann, vorgestern bei Minister von Guérard. Wir selber hatten letzthin einen sehr netten Herrenabend mit Herrn Reichskanzler Müller und den Herren der Reichskanzlei. Jetzt haben wir Einladungen gleich für zwei große Abendessen herausgehen lassen für Ende dieses Monats. Wir hatten schrecklich viel Schulden nach dieser Richtung. Heute abend mit den lieben Kinderchen noch sehr gemütlich. Wir brannten ein Feuer im Garten ab und brieten darin Kartoffeln, eine herrliche Reaktion für mich!

Montag, den 10. März 1930

Schnell ein paar Tagebuchzeilen. Die Krise dauert unvermindert an. Die Dinge entwickeln sich wahrscheinlich und hoffentlich so, wie ich es mir denke und gestern niedergeschrieben habe. Morgen mittag wird Dr. Brüning vom Herrn Reichspräsidenten empfangen, im Anschluß hieran Fraktionssitzung des Zentrums. Ich glaube, daß die Herren dann zustimmen. Zwischendurch gehen Verhandlungen zwischen den vier Parteien der Weimarer Koalition wegen des Finanzprogramms. Vielleicht werden sie in kommender Nacht einig werden. Ich sehe dieser Entwicklung mit einiger Sorge entgegen, da dann evtl. Minister Moldenhauer nicht mehr mitmachen könnte. Morgen nachmittag sind die Abstimmungen II. Lesung. Bis dahin wird und $m u ß$ alles ziemlich klar sein. Minister von Breitenbach ${ }^{119}$ ist heute, $80 \mathrm{Jahre}$ alt, gestorben.

Freitag, den 14. März 1930

Heute kann ich wieder etwas früher im Tagebuch schreiben. Die Dinge laufen so, wie ich letzten Montag sagte. Die „Weimarer" wurden zwar in der Nacht zum Dienstag einig, aber eine sehr erhebliche Abänderung unseres Regierungsprogramm

119 Paul von Breitenbach, geb. 1850, Verwaltungsjurist, 1906-1918 preußischer Minister der öffentlichen Arbeiten und Präsident des Reichsamtes für die Verwaltung der Reichseisenbahnen, 1916/17 auch Vizepräsident des preußischen Staatsministeriums. 
und eine große Verwirrung, weil nun zweierlei Vorlagen da waren. Wir fingen die Dinge aber gleich auf. Um 10 Uhr am Dienstag gab Minister Moldenhauer, nachdem wir zuvor in der Reichskanzlei die Dinge vorbesprochen hatten, eine starke Erklärung für unsere Regierungsvorlage im Reichsrat ab, worauf dieser auf solcher Grundlage mit seinen Beratungen fortfuhr. Ebenso verhielt ich mich am Nachmittag im Preußischen Staatsministerium. Vormittags empfing dann der Reichspräsident den Zentrumsfraktionsführer Dr. Brüning; mit bestem Erfolg. Der alte Herr stellte sich gleichfalls auf den Standpunkt, daß die Kassensanierung dringendst geboten sei. Das genügte dem Zentrum, worauf es mittags in einer Fraktionssitzung mit kleiner Mehrheit beschloß, in zweiter Lesung für die Young-Gesetze zu stimmen. Um 2 Uhr hatten der Reichskanzler, Schäffer und ich eine Besprechung mit den Fraktionsführern der "Weimarex", die gut verlief. So war der vergangene Dienstag von sehr großer Bedeutung als Beginn der Klärung der monatelangen schwelenden Krise.

Am Mittwoch war dann dritte Lesung. Für sie hatten wir in der Reichskanzlei eine groß angelegte Rede des Reichkanzlers fertiggestellt. In der dritten Lesung gab es nicht weniger als zehn namentliche Abstimmungen ${ }^{120}$, alle für die Reichsregierung und ihre Vorlagen, teils mit kleineren, teils aber auch mit recht erheblichen Mehrheiten. Das Ereignis des Tages war das Verhalten der Bayerischen Volkspartei, unter Führung des bayerischen Ministerpräsidenten Dr. Held ${ }^{121}$. Da er eine schriftliche Zusage für die Biersteuer nicht erhalten hatte, sie aber ertrotzen wollte, drohte und führte er schließlich auch durch: die Ablehnung der Young-Gesetze durch die Bayerische Volkspartei! Wir fingen diesen Stoß aber auf, und zwar durch Zulassung und Mitarbeit an zwei Entschließungen der übrigen Regierungsparteien, wobei der Mehrheit noch etwa 15 weitere Stimmen zugeführt wurden und die Bayern ersetzt wurden. Held ist kein Held und ist wütend nach Bayern gefahren. Ich habe an Gesandten von Haniel ${ }^{\mathbf{1 2 2}}$ einen Orientierungsbrief nach München geschickt.

Der gestrige Donnerstag und der heutige Freitag verliefen nach all dem Kampf etwas ruhiger. Persönlich habe ich etwas aufgearbeitet. Der Reichspräsident hat die Young-Gesetze vollzogen und gleichzeitig ein großes Manifest an das deutsche Volk erlassen, das im In- und Ausland außerordentlich großen Widerhall gefunden hat. Etwas hatten wir auch daran mitgewirkt. Die eigentliche Formulierung stammt von Herrn Meißner. Dieser hatte gestern 50. Geburtstag. Große Feier in seiner Wohnung. Ich bin auch dort gewesen, zusammen mit meinen beiden Ministerialdirektoren Zechlin und von Hagenow ${ }^{\mathbf{1 2 3}}$.

120 Einzelheiten in: Schulthess' Europ. Gesch. Kal. 1930, S. $68 \mathrm{ff}$.

121 Dr. Heinrich Held, geb. 1868, Politiker des Zentrums und der Bayerischen Volkspartei, seit 1907 Mitglied des bayerischen Landtages, seit 1924 bayerischer Ministerpräsident.

122 Dr. Edgar Haniel von Haimhausen, geb. 1870, Berufsdiplomat, 1919-1923 Staatssekretär des Auswärtigen Amtes, seitdem Gesandter und Vertreter der Reichsregierung in München.

123 Dr. Viktor von Hagenow, Verwaltungsjurist, seit 1927 Ministerialdirektor in der Reichskanzlei. 
Unsere politische Hauptarbeit gilt jetzt der Kassensanierung, die bis Ende dieses Monats durchgeführt sein muß. Ich glaube, daß wir es schaffen werden, eventuell auch im Wege der Verordnung zur Beseitigung eines Notstandes. Besser wäre natürlich, daß sich die fünf Regierungsparteien zuvor einigten. Solche Einigungsverhandlungen sind auch bereits seit gestern im Gange. Der Herr Reichskanzler ist zu einer sozialdemokratischen Parteiversammlung für zwei Tage nach Stuttgart abgefahren.

Gesellschaftlich war in den letzten Tagen wieder sehr viel los. So am Mittwoch bei Exzellenz Boden ${ }^{\mathbf{1 2 4}}$ und gestern bei Schuberts. Überall wichtig und interessant. Froh sind wir aber, daß wir heute und die nächsten Tage zu Hause sind.

Sonntag, den 16. März 1930

Augenblicklich herrscht etwas Ruhe. Reichskanzler Müller ist über Sonntag nach Stuttgart gefahren, zu einer 10-Jahresfeier der Abwehr des Kapp-Putsches, wobei er eine Rede hielt und die Beamtentreue beim Volksbegehren erwähnte. Nur 43 Fälle auf rund 400000 Beamte! Politisch sind augenblicklich die agrarpolitischen Fragen im Vordergrund. Ich werde wohl für den morgigen Montagnachmittag eine Kabinettssitzung hierfür ansetzen müssen. Nachtragen muß ich noch, daß Präsident Schacht inzwischen abgegangen und vonHerrn Reichskanzler a.D.Luther ersetzt worden ist. Ich begrüße diese Wahl und ich habe an ihr natürlich recht erheblich mitgewirkt. Gesellschaftlich herrscht augenblicklich etwas Ruhe. Herrlich! Wir sitzen gemütlich zu Hause. Heute abend haben wir Magdas Gedichte, die wir zum Drucken geben möchten, durchgesehen. Reizende und gemütliche Beschäftigung.

Heute war Volkstrauertag, äußerst stimmungsvolle Feier im Reichstag in Anwesenheit des Herrn Reichspräsidenten. Der 80 jährige Geheimrat Kahl ${ }^{\mathbf{1 2 5}}$ hielt die Festrede.

Montag, den 17. März 1930

Ich bin jetzt recht fleißig im Schreiben. Heute möchte ich nur festhalten, daß der vormalige spanische Diktator, General Primo de Rivera, in Paris plötzlich gestorben ist. Der Tod dieses Mannes hat mich recht ergriffen. Vor dreiviertel Jahren war ich in Begleitung Stresemanns noch in Madrid sein Gast, heute sind sie beide bereits tot! Ich habe dem spanischen Botschafter ein Beileidschreiben geschickt. Offiziell wird Primo heute totgeschwiegen, ich möchte aber sagen, wie und zwar wie gut ich über diesen Mann gedacht habe. - Heute nachmittag war Kabinettssitzung; Agrarfragen und Kassensanierung beherrschen die Stunde. Ich glaube, daß wir beides unter Dach und Fach bekommen, und zwar noch in diesem Monat. Dann

124 Dr. Friedrich Boden, Wixkl. Geheimer Rat, seit 1913 außerordentlicher Gesandter und bevollmächtigter braunschweigischer Minister zum Bundes- bzw. Reichsrat (zugleich auch für Anhalt und Mecklenburg-Strelitz).

125 Dr. Wilhelm Kahl, geb. 1849, Professor der Rechte an der Universität Berlin, Mitglied der Nationalversammlung und des Reichstages seit 1919 (Deutsche Volkspartei). 
wären wir für lange Zeit über den Berg! Professor Marcel Salzer ${ }^{\mathbf{1 2 6}}$ ist heute in Lichterfelde gestorben. Ich habe ihn oft nachgeahmt und liebe seine Bücher.

Sonntag, den 23. März 1930

Am vergangenen Mittwoch haben wir die erste Lesung unserer Deckungsvorschläge im Reichstag erledigt. Das will allein noch nicht viel besagen. Ab Donnerstag fand dann der dreitägige Parteitag der Deutschen Volkspartei in Mannheim statt, von gewissermaßen geschichtlicher Bedeutung. Er ist für den ruhigen stetigen Gang der politischen Dinge in Deutschland gut verlaufen: er endete sozusagen mit einem starken Bekenntnis für die Große Koalition; dies zeigte namentlich auch die große politische Rede des neuen Parteiführers Dr. Scholz. Wir können also den nächsten Tagen hinsichtlich der Verhandlungsbereitschaft der Deutschen Volkspartei bei den abschlieBenden Finanzverhandlungen mit leidlichem Optimismus entgegensehen. Bis zum 31. März muß alles unter Dach und Fach sein, sonst kommt der Artikel 48 an die Reihe!

Sehr wichtig ist in diesem Zusammenhang auch, daß in den letzten Tagen die Regierungsparteien in den sehr wichtigen Agrarfragen einen Kompromiß gefunden haben. Er befriedigte natürlich noch nicht die Landwirte alle. Am gestrigen Sonnabend nachmittag hatten der Reichskanzler und ich noch die Freude, Herrn Minister a. D. Schiele vom Reichslandbund in der Reichskanzlei zu empfangen, wo er uns dies klar machte. Aber immerhin bedeuten die Anträge eine sehr wesentliche Hilfe für die Landwirtschaft ${ }^{127}$. Diese Anträge kommen am morgigen Montag im Reichstag zur Debatte. Man hofft, sie am Donnerstag schon in allen Lesungen durchgebracht zu haben. Der Landwirtschaft geht es ganz verflucht schlecht, die Tonne Roggen nur $143 \mathrm{RM}$ ! Ich würde es sehr begrüßen, wenn der Beimahlungszwang nach dem Vorschlage des Geheimrats Caro durchgeführt werden könnte.

Gesellschaftlich ist es jetzt erfreulicherweise etwas ruhiger geworden. Nur wir selber geben jetzt hintereinander drei Gesellschaften mit hohen und höchsten Herrschaften; hoffentlich verläuft alles gut: zwei in der Reichskanzlei, eine zu Hause. Gestern lernte ich einen neuen Vetter, Werner Peiner, kennen, der ein sehr beschäftigter Maler in Düsseldorf ist.

Zur 40jährigen Wiederkehr des Entlassungstages von Bismarck schrieb ich in der Vossischen Zeitung einen Artikel über die damalige Zeit und das von mir geplante Bismarck-Museum. Dieser Plan scheint allgemein sehr zu interessieren, denn die Presse greift diese Nachrichten von mir immer gern und interessiert auf.

\section{Sonntag, den 30. März 1930}

In dieser Woche hat sich außerordentlich viel zugetragen. Sturz der Regierung und Schaffung eines neuen Kabinetts Dr. Brüning! Die alte Regierung ist über dem

${ }^{126}$ Marcel Salzer, geb. 1873; bekannter, aus Österreich stammender Vortragskünstler, vor allem humoristischer Gedichte.

127 Gemeint sind die Anträge der Regierungsparteien. Zu den Einzelheiten vgl. C. Horkenbach. Das Deutsche Reich von 1918 bis heute, Berlin 1930, S. 303 f. und Schulthess' Europ. Gesch. Kal. 1930, S. 87 f. 
zwischen Regierung und Parteiführern zustandegebrachten Kompromiß über Arbeitslosenversicherung, Steuersenkung und Steuererhöhung bei der sozialdemokratischen Fraktion gescheitert. Die vier anderen Fraktionen hatten zugestimmt, aber die übergroße Mehrheit der sozialdemokratischen Fraktion versagte ihren Führern, insbesondere dem Reichskanzler Müller, die Gefolgschaft. Das Kabinett beschloß darauf am Donnerstag seinen Rücktritt, der vom Reichspräsidenten sofort angenommen wurde. Er erteilte am Freitag früh Herrn Dr. Brüning den neuen Auftrag. Eine Stunde darauf war Herr Brüning bei mir und batum meine weitere Mitarbeit und Unterstützung, die ich ihm natürlich sehr gerne zusagte. Seine Verhandlungen haben zwei Tage bis heute Sonntag früh gedauert. Ich habe ihm redlich beigestanden. Eine schwere Arbeit! Es ist ein nicht an die Fraktionen gebundenes Kabinett von Dietrich bis Schiele, wobei erhofft aber durchaus unsicher ist, ob ein großer Teil der Deutschnationalen letzterem Gefolgschaft leisten wird. Die Volkskonservativen sind von Treviranus als Rhein-Minister ${ }^{\mathbf{1 2 8}}$ vertreten. Besonders freue ich mich, daß es mir gelungen ist, Herrn Dietrich zum Vizekanzler zu bestellen. Hinter den Kulissen war an dieser Koalition schon seit Wochen mitgearbeitet worden, namentlich von Treviranus und General von Schleicher ${ }^{\mathbf{1 2 9}}$. Was wir feststellen konnten, ist nicht alles schön gewesen. Sie wollten zumal meinen beiden Ministerialdirektoren von Hagenow und Zechlin ans Leder, beides habe ich aber sofort abwehren können. Mich hatte man angeblich zunächst zum kombinierten Verkehrsminister mit Eisenbahn und Post zusammen vorgesehen, und Treviranus sollte mein Nachfolger werden. Ob es wahr ist? Ich bin jedenfalls froh, daß Brüning als erste Handlung mich um weitere Mitarbeit bat. Reichskanzler Müller trifft der Schlag mit vollem Recht ziemlich schwer, aber in seiner Ruhe und Sachlichkeit ist er sehr gefaßt, wahrscheinlich weniger seine Damen.

Gestern abend hatten wir zu Hause ein wohlgelungenes Fest mit drei Reichskanzlern: Marx ${ }^{\mathbf{1 3 0}}$, Müller und Brüning, von denen allerdings letzterer schließlich begreiflicherweise doch nicht kommen konnte. Außerdem waren die Reichsminister von Guérard und Schätzel mit ihren Damen da, ferner Herr und Frau von Hagenow, General von Schleicher und die Meinen. Drei Tage vorher hatten wir ein großes Fest in der Reichskanzlei, mehr für die Freunde, 4.0 Gedecke. Sehr gelungen, aber in dieser Woche war es eine Quälerei, sich solchen Dingen hergeben zu müssen. Ich hatte rasend zu tun und sehr große Verantwortung. Jetzt steht mir die Verabschiedung des alten und die Einführung des neuen Reichskanzlers bevor, zusammen mit der Reichsregierung. Hinzu kommt, daß es unseren lieben Kinderchen eigentlich recht schlecht geht, zum ersten $\mathrm{Mal}$ in ihrem kurzen Leben. Namentlich Bübi ist sehr krank, $40^{\circ}$ Fieber. Drüsenentzündung. Hoffentlich wird bald alles wieder gut. Sie kommen so von Kräften!

128 Unter "Rhein-Ministex" ist der Reichsminister für die besetzten Gebiete zu verstehen.

129 Einzelheiten etwa bei K. D. Bracher, Die Auflösung der Weimarer Republik, 3. Aufl., Villingen 1960, S. $303 \mathrm{ff}$.

130 Dr. Wilhelm Marx, geb. 1863, Jurist und Zentrumspolitiker; 1899-1918 Mitglied des preußischen Abgeordnetenhauses, seit 1910 des Reichstages. 1923-1925 und 1926-1928 Reichskanzlex, 1925 vorübergehend preußischer Ministerpräsident. 
Montag, den 31. März 1930

Heute der erste Tag des neuen Kabinetts. Ich hatte vor ihm einige Sorgen. Um 10 Uhr hatte ich meinen letzten Vortrag beim bisherigen Reichskanzler Müller, der anschließend hieran zum Herrn Reichspräsidenten ging. Kurz vor 11 Uhr hatte ich den neuen Herrn Reichskanzler Dr. Brüning gebeten, den ich unten im Vestibül abholte und dann ins Reichskanzlerzimmer führte, wo er von Herrn Müller begrüßt wurde. Für 11 Uhr hatte ich die gesamten Beamten, Angestellten und Arbeiter der Reichskanzlei in der Bibliothek aufgebaut, woich dann einelängere Rede aufdie beiden Herren Reichskanzler hielt. Es antwortete zunächst Müller und dann Brüning. Abschließend gingen wir „die Front" ab mit Händedrücken aller Anwesenden. Vor solchen Sachen habe ich einen gewissen Bammel, damir „höfische "Dingenichtsehrliegen. Ich glaube und höre, daß ich es aber recht gut gemacht habe. Dann erste sachliche Aussprache mit dem neuen Herrn über die Regierungserklärung, deren ersten Entwurf ich ihm vorlegte. Vor Tisch konnte ich noch allen Reichsministern den ersten Aufguß übersenden. Um 1/24. Uhr die erste Kabinettssitzung mit vorübergehendem ersten Photographieren. Die Kabinettssitzung verlief recht gut, nur, wie zu erwarten, fürchterliche Tiraden des Herrn Reichsernährungsministers Schiele. Darauf zweiter Aufguß der Regierungserklärung, nun leider schon recht viel länger. Noch abends bekommen alle Minister wieder ihr Stück. Morgen 9 Uhr früh haben wir die nächste Kabinettssitzung.

Heute abend ist Einweihung des Pressehauses, wohin auch ich eingeladen war, sagte aber ab wegen Vorbereitung der Regierungserklärung.

Freitag, den 4. April 1930

Gestern war ich zu müde und elend, um zu schreiben. Ich hätte den recht großen Sieg des Kabinetts Brüning erwähnen müssen. Mit der verhältnismäßig großen Mehrheit von 65 Stimmen siegte es über die Linke. Im letzten Augenblick waren die Deutschnationalen unter Führung von Hugenberg selber vollständig umgefallen. Noch am Mittwoch war alles zweifelhaft. Es hieß, die Sozialdemokraten würden ihr Mißtrauensvotum so begründen, daß die Kommunisten nicht zustimmen könnten. Stattdessen motivierten sie es aber nicht, so daß die Unterstützung anzunehmen war und auch tatsächlich eintrat. Alles hing also an der Haltung von rechts. Sehr viel Mühe haben wir uns um diese Unterstützung nicht gegeben. Brüning und ich sagten uns mehrfach, daß eine Annahme des Mißtrauensvotums eigentlich das angenehmste sein würde. Dann würde sofort aufgelöst und alle Schwierigkeit und Reiberei mit dem Reichstag wäre zu Ende gewesen. Stattdessen wurde ich aber in der Nacht vom Mittwoch zum Donnerstag von Minister Schiele angerufen, der gerade mit dem deutschnationalen Fraktionsführer Oberfohren zusammensaß. Diese Besprechung ist recht historisch geworden, wie nebenstehende Pressenotiz am nächsten Morgen zeigte. Herr Schiele teilte mir mit, daß die Verhandlungen mit den Deutschnationalen ganz gut ständen, daß ihm aber noch eine Besprechung zwischen Brüning und Oberfohren erforderlich erscheine. Ich glaubte ihm eine solche versprechen zu 
können, und wir verabredeten für den gestrigen Morgen, kurz vor $10 \mathrm{Uhr}$, wo wir im Reichstag Kabinettssitzung hatten, eine Besprechung: Brüning, Schiele, Pünder, Oberfohren. Dem Reichskanzler teilte ich dies gestern morgen frühzeitig mit, und er war mit meinem Vorschlage und getroffener Disposition durchaus einverstanden. Die Besprechung hat dann stattgefunden: durchaus zufriedenstellend. Den Niederschlag bildete die zweite Rede Brünings am gestrigen Sitzungstage. Auf meinen Vorschlag bezog er sich auf Fragen anderer vorangegangener Redner, so Scholz und Stöhr ${ }^{131}$, und sprach auch vor Hugenberg, damit keinerlei Abhängigkeit konstruiert werden konnte. Die kurzen - durchaus selbstverständlichen - Mitteilungen des Reichskanzlers bezogen sich auf die zeitliche Vorlage des Agrarprogramms. Sie hatten die Wirkung, daß nun Hugenberg für den Augenblick von seinem Mißtrauensantrag Abstand nahm. Das Verhalten Hugenbergs war ganz furchtbar blamabel. Während der Sitzung hatte ich die Auflösungsorder in meiner roten Kabinettsmappe zur Hand. Die Presse hat über meine rote Mappe allerhand zusammenorakelt.

Nach dem Siege hatten wir nachmittags sofort eine Parteiführerbesprechung in der Reichskanzlei über die Deckungsfragen. Noch recht unergiebig. Es zeigte sich aber, da $\beta$ die Reichsregierung fest bleiben muß, dann wird sie schon siegen. Ich sorge dafür mit durch kräftige und optimistische Kommuniqués, die gut wirken. Heute beschäftigte sich das Kabinett mit der taktischen Behandlung der Deckungsvorschläge. Wir haben beschlossen, an der 75\% igen Biersteuer[erhöhung] festzuhalten. In drei oder vier Tagen muß der Steuerausschuß fertig sein.

Vorgestern abend hatten meine Frau und ich die feinste Fete, die wir wohl überhaupt in dieser schweren Zeit gegeben haben: in der Reichskanzlei, mit dem englischen und spanischen Botschafter, den Gesandten von Österreich, Litauen, Bayern, Braunschweig, Sachsen, Vizekanzler Dietrich, Meißner, Köpke ${ }^{132}$ usw. 34. Personen, wohlgelungen. Meine gute alte Mutter war auch dabei; ich glaube, sie war ganz stolz.

Mittwoch, den 9. April 1930

Wir leben nach wie vor in sehr aufgeregten Zeiten. Äußeres Zeichen für mich: vom frühen Morgen bis in die tiefe Nacht eine Sitzung nach der anderen.

Also, politisch ist mit dem lieben Reichstag noch keineswegs alles in Ordnung. Nach zwei schweren Tagen haben wir gestern nachmittag den Agrarkompromi $\beta$ zustande gebracht, in der Gestalt des Gesetzes „zum Schutze der Landwirtschaft“. Im Anschluß daran hatten wir gestern nachmittag und spät abends Parteiführerbesprechung, jetzt von den Demokraten bis zu den Volkskonservativen. Kurz vor 11 Uhr abends waren wir einig. Das hat natürlich den Deckungsfragen, auf die es uns vor allem ankommt, etwas Auftrieb gegeben. Allerdings ist heute morgen im Steuerausschuß die Biersteuer gefallen. In der Zwischenzeit haben aber private Parteiführerbesprechungen stattgehabt, deren Ergebnis ich heute nachmittag in der

131 Franz Stöhr, geb. 1879, ursprünglich Funktionär des Deutschnationalen Handlungsgehilfenverbandes, seit 1924 Mitglied des Reichstages (NSDAP).

132 Dr. Gerhard Köpke, Ministerialdirektor und Leiter der Abteilung II im Auswärtigen Amt. 
Ministerbesprechung zum Vortrag brachte. Ich hatte wieder mal die Sache in der Hand: statt 75\% nur 50\% Biersteuer-Erhöhung, daneben 0,10\% Umsatzsteuer-Erhöhung und eine kleine Warenhaussteuer, daneben die kleinen Bierbrauereien aus der Biersteuer-Erhöhung herausgelassen. Das Kabinett billigte diese Vorschläge. Von $1 / 26$ Uhr ab hatten wir dann das Geraufe mit den Parteiführern. Schließlich völlige Einigung auf ungefähr dieser Linie bis auf die - Bayern! Sie werden sich die Sache aber noch bis morgen früh überlegen. Evtl. muß es ohne sie versucht werden, was aber kaum gelingen dürfte, da alsdann die Deutschnationalen - jedenfalls nicht geschlossen - mitmachen werden. Wir können das aber in Ruhe abwarten. Wenn die Steuern abgelehnt werden, wird eben übermorgen der Reichstag aufgelöst. Mit dem neuen Reichskanzler Brüning arbeite ich ausgezeichnet zusammen. Er ist sehr nett zu mir und hört außerordentlich auf mich. Ich glaube, wir könnten auch wieder eine gute Ehe abgeben. Aber wer weiß, wie lange die Herrlichkeit dauert!

\section{Sonntag, den 13. April 1930}

Am heutigen Sonntag finde ich etwas Muße zu rückschauenden Betrachtungen. Die erste Schlacht wäre geschlagen: am gestrigen Sonnabend wurde die zweite Lesung aller Gesetze zu Ende geführt, und zwar mit Erfolg. Die Mehrheiten waren gering, abwechselnd von 9 bis etwa zu 60 Stimmen, ebenso wurde ein kommunistisches Mißtrauensvotum mit geringer Mehrheit abgelehnt. Eine solche Siedehitze habe ich im Reichstag noch nicht erlebt und werde sie wohl auch so bald nicht wieder erleben. Dramatische Ereignisse waren in den letzten Tagen vorangegangen. Zunächst hatten die Bayern den Steuerkompromiß nicht mitgemacht, sie wollten nur $40 \%$ Biersteuer[erhöhung] bewilligen. Nachdem ihnen das abgelehnt war, fielen sie schließlich in der Nacht zum Freitag doch um. Am Freitag früh konnte ich als erster dem Reichskanzler Brüning mitteilen, daß dieses Ereignis passiertsei. Wir hatten dann am frühenMorgen eine Besprechung mitdem Prälaten Leicht ${ }^{\mathbf{1 3 3}}$. Das Nachgeben hatte insofern einen unangenehmen Beigeschmack, als die Bayern eine andere Staffel verlangten. Schließlich einigte man sich mit ihnen auf dieser Basis, die inzwischen Ministerialdirektor Ernst ${ }^{134}$ mit dem Dr. Horlacher ${ }^{135}$ verabredet hatte. Gegen Mittag hatten der Reichskanzler und ich sodann eine Besprechung mit Dr. Oberfohren und Graf Westarp über die Haltung der Deutschnationalen. Sie erklärten uns, daß sie in der zweiten Lesung am Sonnabend bestimmt gegen die Steuervorlagen stimmen würden, dagegen ihre Haltung für die dritte Lesung am Montag vorbehalten würden. Über diese deutschnationale These hatten wir dann abends 1/27 Uhr Ministerbesprechung mit anschließender Parteiführerbesprechung

133 Johann Leicht, geb. 1868, Prälat, Politiker des Zentrums und der Bayerischen Volkspartei; seit 1913 Mitglied des Reichstages, seit 1920 Fraktionsvorsitzender der BVP.

134 Leiter der Abteilung II im Reichsfinanzministerium (nicht zu verwechseln mit dem Ministerialdirektor Dr. Ernst vom preußischen Ministerium für Handel und Gewerbe).

135 Dr. Michael Horlacher, geb. 1888, Jurist und Agrarpolitiker, Direktor der Bayerischen Landesbauernkammer, Mitglied des Reichstages seit 1924. (Bayerische Volkspartei). 
bis wieder $10 \mathrm{Uhr}$ abends, wo wir ein Junktim zwischen den Agrarvorlagen und den Deckungsvorschlägen festlegten, in der Art, da $\beta$ den Zollvorlagen ein $§ 1$ a eingefügt wurde, daß die Zollvorlagen (Agrarprogramm) nur in Kraft treten sollten, wenn auch die Deckungsvorlagen angenommen würden. Schon abends spät holten wir die Unterschriften aller sechs Regierungsparteien ein. Am Sonnabend früh hatte ich dann eine längere, sehr wichtige Besprechung mit Dr. Oberfohren, in der ich dem deutschnationalen Fraktionsführer Mitteilung von diesem Geschehnis machte, mit dem Hinzufügen, daß bei Ablehnung Reichstagsauflösung stattfinden werde ${ }^{136}$. Diese neue Wendung hat dann bei den Deutschnationalen den Ausschlag gegeben, dahingehend, daß über die Hälfte der Fraktion nach vorangegangener Freigabe der Abstimmung sich auf den Regierungsboden stellte. Am Sonnabend früh diktierte ich dann eine knappe Regierungserklärung für Reichskanzler Brüning, von der ich wiederum die Genugtuung hatte, daß sie fast wörtlich von ihm so gelassen wurde. Ich glaube, es waren wenige, aber gemeißelte Sätze, die dann nachher im Reichstag ganz große Wirkung hatten. Die Reichstagssitzung war dann am gestrigen Sonnabend bereits um $12 \mathrm{Uhr}$; ich brachte dorthin die Auflösungsorder mit, die ich dann dauernd bei mir hatte, da wir bei ungünstigem Abstimmungsergebnis aufgelöst hätten. Ich habe sie wieder ungenutzt mit nach Hause nehmen können; abends gegen 7 Uhr war der Spuk zu Ende. Am morgigen Montag ist die dritte Lesung. Es ist keineswegs ausgeschlossen, daß dann ein Unglück passiert, da bei der knappen Mehrheit Zufälligkeiten nicht ausgeschlossen sind. Persönlich bin ich sehr gespalten. Ich habe zwar dauernd an der Linie mitgearbeitet, daß wir auf parlamentarischem Wege alles erledigen, auf die Dauer kommen wir an einer Reichstagsauflösung aber sowieso nicht vorbei. Und ich fürchte die nervenbeanspruchende Arbeit nächstens mit dem Reichstag. Und außerdem werden wir sobald nicht wieder eine so günstige Wahlparole erlangen wie gerade jetzt. Alles in allem sehe ich also dem morgigen Montag mit großer Seelenruhe entgegen. Die Zusammenarbeit mit dem neuen Reichskanzler macht mir viel Freude. Ich habe auch das Empfinden, daß er auf meine Mitarbeit großen Wert legt. Jedenfalls kommen wir beide bestens aus. Froh war ich, daß der heutige Sonntag sitzungsfrei war. Ich habe mich jedenfalls heute tüchtig geaalt.

Karfreitag, den 18. April 1930

Karfreitag, Tag der Einkehr und Ruhe.

Die letzte Woche vor Ostern war noch viel los in der Politik. Der vergangene Montag, der 14. April, brachte die positive Entscheidung im Reichstag. Von morgens bis zum späten Nachmittag wurde dauernd abgestimmt. Es herrschte eine unbeschreibliche Spannung, vielleicht wie noch nie seit Bestehen des Reichstags. Die wichtigsten Abstimmungen, die über Sein und Nichtsein dieses Reichstags ent-

136 Aus der Niederschrift der Parteiführerbesprechung vom 11. April 1930: „.. Es bestand Übereinstimmung darüber, daß als notwendige Entscheidung die Auflösung des Reichstages anzusehen ist. Sollte z. B. lediglich die Mineralwassersteuer abgelehnt werden, so soll eine Auflösung des Reichstages nicht in Frage kommen." Akten Reichskanzlei, Bd 1021. 
schieden, brachten Mehrheiten von 3 bis 7 Stimmen! Ich arbeitete fieberhaft hinter den Kulissen. Nach erreichtem Erfolg dankte mir Reichskanzler Brüning sehr herzlich und mit feuchten Augen für die treue Mitarbeit. Die weiteren Tage dieser Woche brachten dann aber, trotzdem der Reichstag bis Anfang Mai in die Ferien gegangen ist, noch viel Arbeit.

Wir bereiteten das Ostprogramm ${ }^{\mathbf{1 3 7}}$ vor, für das Minister Schiele zunächst recht unklare und uferlose Vorschläge gemacht hatte. Sehr unangenehm war die Angelegenheit des Panzerschiffes B. Nicht ohne Mitwirkung des Reichswehrministeriums hatte der Reichsrat die erste Baurate für dieses zweite Schiff eingesetzt. Nach eingehender Debatte beschloß das Kabinett, keine Doppelvorlage zu machen ${ }^{\mathbf{1 3 8}}$. Aber das Schiff ist damit noch nicht bewilligt und gebaut!

\section{Donnerstag, den 24. April 1930}

Endlich mal schöne Zeiten! Ostern entzückend in der Familie verlebt. Dienstag nicht viel los. Der neue Reichskanzler ist in Badenweiler. Ich bin nur vormittags auf dem Büro, die Nachmittage mache ich blau. Mit den Kindern im Garten, zwei kleine Ausflüge machten wir auch schon. Heute war unseres Ältesten erster Schultag! Vater, Mutter und Schwesterchen brachten ihn hin. Unvergeßlicher Tag für Eltern und Kind.

\section{Donnerstag, den 1. Mai 1930}

„Der Mai ist gekommen!“ und damit auch wieder viel Arbeit für mich. Jetzt ist das Kabinett wieder versammelt, und wir beraten Ostprogramm und Agrarfragen. Morgen beginnt das Plenum mit dem Etat 1930.

Lugano. Mittwoch, den 28. Mai 1930

So lange hat es bisher mit dem Tagebuch wohl noch nicht gedauert. Aber der Abhaltungen waren bisher gar viele. Die Zusammenarbeit mit Reichskanzler Brüning geht ausgezeichnet. Er ist nicht der Mann des Diktats, der nur bestimmt und nicht auf andere hört. Im Gegenteil habe ich, glaube ich, recht viel Einfluß auf ihn. Aber auf der anderen Seite habe ich in ihm zum ersten Mal, hier darf ich es offen aussprechen, einen Chef mit sehr tiefen Fachkenntnissen, der gewissen großen Zielen nachgeht und sich nicht treiben lassen will. Seine Hauptstärke sind offensichtlich wirtschaftspolitische Dinge, aber sein großer Verstand ermöglicht es ihm, auch auf anderem Gebiet sehr bald eine sehr klare Auffassung zu haben. Neulich war er eine Woche auf Urlaub; da habe ich in seiner Abwesenheit alles vorbereitet,

137 Angeregt durch ein Schreiben Hindenburgs an Reichskanzler Müller vom 18. März 1930 (aus Anlaß der Unterzeichnung des Zustimmungsgesetzes zum deutsch-polnischen Liquidationsabkommen), bereitete die Regierung den Entwurf eines „Gesetzes über Hilfsmaßnahmen für die notleidenden Gebiete des Ostens" vor. Die wichtigsten Textstellen der Hindenburg-Botschaft in: Schulthess' Europ. Gesch. Kal. 1930, S. 78 f.

138 Vgl. Anm. 56. 
namentlich hinsichtlich des sogenannten Ostprogramms, das durch die Regierungserklärung besonders angekündigt war und das den besonderen Wünschen des Herrn Reichspräsidenten entsprach. Hier gab es zunächst ein ziemlich heilloses Durcheinander, indem sowohl das Innen- als auch das Finanz- und das Ernährungsministerium die Federführung haben wollten. Schließlich haben wir uns gut geeinigt, nicht zuletzt durch die vermittelnde Tätigkeit der Reichskanzlei.

Besonders schwierig war die Zusammenarbeit mit Preußen. Ernährungsminister Schiele, der parteimäßig natürlich nachweisen mußte, daß jetzt etwas ganz Neues gerade im Hinblick auf die preußische Verwaltung kommen werde, war hierfür natürlich besonders wenig zu haben. Wir haben es aber doch durch gesetzt, und zwar in enger Zusammenarbeit mit dem Präsidenten Klepper von der Preußenkasse ${ }^{139}$, der von der Preußischen Staatsregierung mit allen Vollmachten ausgerüstet war. Wichtig und schwierig war auch die Gewinnung des Vizekanzlers Dietrich zum Ostprogramm. Schließlich waren aber alle unter einem Hut, und wir faßten vor etwa zehn Tagen einen einstimmigen Kabinettsbeschluß, der gewi $\beta$ auch die preußische Zustimmung finden wird. Hoffen wir auch, daß der Erfolg in der Praxis nicht ausbleiben wird. Nach dieser Richtung werde ich starke Zweifel nicht los, ebenso wie hinsichtlich der ganzen agrarpolitischen Maßnahmen unserer Regierung, die wir auf Vorschlag Schieles dauernd treffen. Sie beziehen sich fast ausschließlich auf zollpolitische Maßnahmen. Was uns nottut, ist nach meiner Meinung eine langsame, aber völlige Umstellung in der landwirtschaftlichen Produktion, weg vom Körnerbau, hin zum Futtermittelbau, Viehzucht und Milch- und Eierwirtschaft, und vor allem Rationalisierung. Dazu gehört natürlich Kapital, und schnell wird es nicht gehen. Die Frage ist aber, ob die jetzigen - m. E. - recht altmodischen Maßnahmen noch etwas nutzen werden. Aber Minister Schiele ist ja dieser Auffassung, und ich würde mich herzlich freuen, wenn ich unrecht haben sollte.

Minister Dietrich, unser Vizekanzler, ist neulich mit dem Herzen nicht unbedenklich zusammengeklappt. Er hat mehrere Wochen Urlaub nehmen müssen und befindet sich jetzt in Marienbad. Anfang Juni wird er wieder da sein. Ich habe ihn dringend nötig, nicht nur wegen seinen großen Erfahrungen, sondern auch wegen seines Einflusses auf die Demokraten und die ganze Linke. Dietrich verkörpert eine starke Kraft. Im Gegensatz zu Minister Moldenhauer, den ich nicht mehr so hoch schätze wie in der ersten Zeit seiner Ministerherrlichkeit. Er ist zweifellos ein sehr geschickter Mann, der schnell Situationen erfaßt, aber ein Mann ohne eine tiefe Weltanschauung, von dem kein großer Impuls ausgeht. Im starken Gegensatz dazu steht seine große Redefreudigkeit, die ihn langsam der Gefahr aussetzt, politisch um jeden Kredit zu kommen. Noch heute steht im Wirtschafts-Tageblatt eine sehr abfällige Kritik über unseren verehrten Reichsfinanzminister.

Seine Stellung ist im Augenblick so sehr schwierig und daneben so wichtig, weil der noch nicht verabschiedete Haushaltsplan 1930 trotz aller vorsichtigen Aufstellung ein riesiges Loch aufweisen wird, das noch in diesem Monat gedeckt werden

139 Otto Klepper, Präsident der Preußischen Zentralgenossenschaftskasse („Preußenkasse“), später (1931/32) preußischer Finanzminister in der Regierung Braun. 
muß. Verursacht diesmal vom starken Rückgang der Einnahmen und sodann durch die immer noch sehr hohe Arbeitslosigkeit. In Summa ein Loch von rd. 430 Millionen, selbst wenn die Beiträge zur Arbeitslosenversicherung um 1\% auf 4.1/2\% erhöht und für rd. 80 Millionen Reformen durchgeführt werden. Gerade gestern hat sich das Kabinett mit diesen Fragen beschäftigt. Ich hatte die Sitzung noch angesetzt, konnte aber leider nicht daran teilnehmen. Nach meiner Meinung kommen wir aus dem Dalles nicht mehr heraus, wenn wir nicht die Löhne, Gehälter und auch die Preise senken. Der Reallohn müßte möglichst der gleiche bleiben wie bisher, aber eine allgemeine Senkung des Preisniveaus wäre nötig. Das sind natürlich etwas revolutionäre Mittel; ob man sie durchführen könnte, ist wohl zweifelhaft. Aber nötig wäre es sicher. Ich glaube kaum, daß sich das Kabinett zu solchen Maßnahmen aufraffen könnte. Deshalb bedauere ich meine Nichtteilnahme an den gegenwärtigen Kabinettsberatungen, aber in diesem Stadium könnte ich doch nicht mehr viel helfen.

Überhaupt fiel meiner Frau und mir die Abreise von Berlin etwas schwer. Aber wir haben sie angetreten, weil wir beide schließlich die Erholung auch einmal nötig hatten. Namentlich auch Reichskanzler Brüning war furchtbar nett in dieser Frage und zwang mir richtig den Urlaub auf. So sind wir seit drei Tagen, dem vergangenen Sonntag vormittag, in Lugano und in der Villa Castagnola abgestiegen. Es ist hier wunderschön, aber das Wetter läßt leider sehr zu wünschen übrig. Trotzdem erholen wir uns hier prächtig und lassen uns durch täglichen Regen die gute Laune nicht verderben. Am Sonntag nachmittag machten wir gleich einen schönen Spaziergang am Ufer entlang um den Monte Salvatore herum und besichtigten den ganzen prächtigen Ort. Am Montag früh waren wir in Gandria, einem äußerst malerischen Nest, ganz in italienischer Armut und Schönheit gebaut. Überhaupt, die ganze Gegend ist hier viel italienischer als wir uns das vorgestellt hatten. Kaum, daß die Bevölkerung etwas Deutsch versteht. Am Montag nachmittag machten wir ein Schiffstourchen nach Ponto Tresa und lernten die herrlichen Ufer des tiefgrünen Sees kennen. Am gestrigen Dienstag badeten wir im See. Hier gleich gegenüber dem Hotel von dem dazugehörigen Badehäuschen aus. Unvergleichlich schön! Nachmittags fuhren wir zusammen mit der Drahtseilbahn auf den Monte Bré, $930 \mathrm{~m}$ hoch. Die Aussicht war ganz herrlich. Das gute Wetter dauerte gerade noch so lange, daß wir die Aussicht genießen konnten. Dann aber setzte ein furchtbares Unwetter ein. Sehr tapfer gingen wir zu Fuß zurück, liehen uns von dem freundlichen Gipfelwirt einen Schirm, den wir unten wieder aufgaben. Die Wanderung war sehr feucht, aber doch gemütlich, zwei ganze Stunden. Seit der Zeit ist das schöne Wetter vorbei. Heute wollten wir nach dem Como-See fahren, mußten es dann wegen des schlechten Wetters aber bleiben lassen. Stattdessen haben wir heute einen schönen Bummel durch die Stadt gemacht mit einigen Einkäufen in den alten Winkeln dieser malerischen Stadt. Heute nachmittag fuhren wir trotz des wenig schönen Wetters mit dem Schiffchen nach Morcote, mit einer sehr malerischen, aber doch recht zerfallenen alten Kirche auf schwindelnder Höhe. Nachher gemütliches Kaffeestündchen bei einem deutschsprechenden Wirt. 
Lugano. Dienstag, den 3. Juni 1930

Gleich schlägt die Abschiedsstunde. Ich muß schon mit Bleistift schreiben, da mir keine Tinte mehr zur Hand ist. Es war herrlich hier die neun Tage. Unterkunft in der Villa Castagnola, etwas teuer und unpersönlich, aber sonst sehr behaglich. Besonders schön das Badehaus direkt beim Hotel am See, wo ich fast täglich gebadet und geschwommen habe. Wir haben auch herrliche Touren gemacht. Unvergleichliche Eindrücke! Warm war es gerade nicht. Leider zwischendurch auch recht viel Regen, der dann aber doch schnell wieder auftrocknete. Gleich fahren wir in einem durch nach Hause. Und damit, lieber Leser, auf Wiedersehen in Berlin!

\section{Dienstag, den 10. Juni 1930}

Wieder glücklich zu Hause. Seit Donnerstag bin ich tüchtig im Geschirr. Reichskanzler Brüning fuhr Freitag abend für eine Woche nach Freudenstadt. Ich brachte ihn zur Bahn. Wir haben die beiden Tage tüchtig zusammengearbeitet. Ich kam gerade recht zu der sehr wichtigen Donnerstags-Kabinettssitzung. Wir beschlossen die „Reichshilfe ${ }^{\mathbf{1 4 0}}$ und die 1\%ige Erhöhung der Arbeitslosenunterstützung und noch verschiedenes mehr. Die Presse ist durch unsere Beschlüsse sehr wenig erbaut. Vielleicht bessert es sich noch im Reichstag. Wir müssen unbedingt zu einer Senkung des gesamten Preisniveaus kommen, dazu gehört leider auch die Senkung der Gehälter. Aber das darf man einstweilen noch kaum laut sagen. Heute ist aber vom Arbeitsminister der sicher noch einmal berühmt werdende Schiedsspruch für die nordwestdeutsche Gruppe ${ }^{\mathbf{1 4 1}}$ für verbindlich erklärt worden, der gleichfalls eine Lohnsenkung vorsieht.

Die Pfingsttage haben wir gemütlich verlebt. Die berühmte Kaiser-WilhelmGesellschaft hat mich zu ihrem Ehrenmitglied ernannt, mit ihrem schönen goldgrünen Abzeichen. Vorgestern erhielt ich die Urkunde von Exzellenz von Harnack ${ }^{\mathbf{1 4 2}}$, indem er meine angeblich großen Verdienste um Förderung von Wissenschaft und Forschung hervorhob. Eine hohe Ehre für mich.

140 Unter „Reichshilfe" (auch „Notopfer“ genannt) wurde eine Kürzung der Gehälter der Festbesoldeten im öffentlichen Dienst und in der Privatwirtschaft, soweit sie nicht versicherungspflichtig waren, verstanden. Ferner sollten Zuschläge zur Einkommensteuer der Ledigen erhoben und Kürzungen an den Tantiemen der Aufsichtsräte vorgenommen werden. Die Vorlage unterlag in den folgenden Wochen noch manchen Änderungen.

141 Ein in Bad Oeynhausen gefällter Schiedsspruch hatte für die Eisenindustrie der Gruppe Nordwest eine ErmäBigung der übertariflichen Löhne und Gehälter von $71 / 2 \%$ vorgesehen. Die Arbeitgeber mußten sich jedoch verpflichten, eine Preisermäßigung ihrer Erzeugnisse über das Maß der ersparten Lohn- und Gehaltssummen hinaus vorzunehmen.

142 Dr. Adolf von Harnack, geb. 1851, Theologe und Professor an der Universität Berlin. Seit 1911 Präsident der Kaiser-Wilhelm-Gesellschaft (heute: Max-Planck-Gesellschaft), an deren Gründung er maßgebend beteiligt war. Harnack starb am Tage dieses Tagebucheintrages in Heidelberg. 
Sonntag, den 22. Juni 1930

Heute große Fronleichnamsprozession in der Hedwigskirche. Ich habe mich beteiligt, nicht aus Eitelkeit, sondern aus Pflichtgefühl. Ich bin immer ganz erschüttert über diese Manifestation unseres Glaubens in dem heidnischen oder doch zum mindesten nicht sehr christlichen Berlin. Heute wieder riesige Beteiligung. Ich war mit Reichskanzler Brüning dort. Noch viele andere hohe Würdenträger. Am Schluß dankte uns der Bischof herzlich für die Beteiligung.

Im Politischen haben wir wieder einmal sehr schlimme Zeiten. Moldenhauer hat gestern seinen Abschied erhalten. Wer sein Nachfolger wird, steht noch aus ${ }^{\mathbf{1 4 3}}$. Ich hoffe Vizekanzler Dietrich. Allmählich möchte ich den Spaß an der Mitarbeit verlieren. Wir kommen aus den Krisen nicht heraus, und die Arbeit leidet Not. Diesmal dreht es sich um die Reichshilfe der Festbesoldeten, die ich im Großen für absolut notwendig halte.

\section{Dienstag, den 1. Juli 1930}

Heute der erste Tag der deutschen Freiheit am Rhein! Im Laufe der harten Tagespolitik geht die Freude über dieses Ereignis leider nur zu leicht verloren. Auch wird heute als selbstverständlich angesehen, was es vor gar nicht langer Zeit noch nicht war. Wer wie ich seit Jahren all diese Dinge mitgemacht hat, weiß, $\mathrm{da} ß$ es anders ist. Aller Augen richten sich am heutigen Tage auf die hehre Gestalt Gustav Stresemanns, der nicht mehr unter uns weilt. Seiner Gattin habe ich heute einen persönlichen Brief geschrieben, nicht von amtswegen, sondern von Mensch zu Mensch. Es liegt eine tiefe Tragik in dem Geschick dieses Mannes, der den heutigen Tag, dem sein Wirken galt, nicht mehr erleben durfte. Heute früh habe ich mit Herrn Reichskanzler Brüning an seinem Grabe einen riesigen Lorbeerkranz niedergelegt, ebenso übrigens auf dem Garnison-Friedhof für die gefallenen Helden des Weltkrieges.

Gestern abend war anläßlich der Rheinland-Räumung großer militärischer Zapfenstreich im Stadion. General von Stülpnagel hatte dazu eingeladen. Auch Herr Reichskanzler Brüning war erschienen. Wir saßen in derEhrenloge. Es war für mich als alten Soldaten ein unvergeßliches Schauspiel. Nicht nur die Militärmärsche, sondern namentlich am Schluß der Zapfenstreich bei Fackelbeleuchtung, gespielt von sämtlichen Musikkorps des III. Wehrkreises. Zwischendurch das grandiose Feuerwerk mit mächtigem Getöse, schlimmer fast als im Weltkriege im Trommelfeuer.

Am Tage vorher, am vorgestrigen Sonntag, ein anderes Fest, in demselben Stadion, der 28. Märkische Katholikentag unter Leitung von Erich Klausener. Glänzend gelungen. Vielleicht manchmal etwas zu wenig religiös und zu theatralisch, aber eine riesige religiöse Demonstration des märkischen Katholikentums. Es

143 Nach einem Vermerk Pünders vom 20. Juni 1930 (Akten Reichskanzlei, Bd 1308) war von seiten Brünings daran gedacht worden, den preußischen Finanzminister Dr. HöpkerAschoff, in Personalunion mit seinem preußischen Amt, das Reichsfinanzministerium übernehmen zu lassen. 
sollen 60000 Menschen dort gewesen sein. Es ist bei uns bald wie bei den alten Römern und Griechen, die großen Volksfeste werden im Stadion gefeiert.

In der Politik sieht es etwas besser aus. Vizekanzler Dietrich ist Reichsfinanzminister geworden. Wir haben in langwierigen Kabinetts-Sitzungen unser Programm etwas geändert: Beamtenreichshilfe auf $2 \frac{1}{2} \%$ herabgesetzt, dafür 5\% Zuschlag zur Einkommensteuer dazu genommen und die Ledigensteuer etwas ausgebaut. Außerdem, was sehr wichtig war, die freien Angestellten (also auch die Redakteure!) vom Notopfer befreit. Ein besonders kluger Schachzug der Regierung, an dem ich nicht ganz unbeteiligt war, war eine öffentliche Sitzung des Reichsrates am vergangenen Sonnabend, wo Reichskanzler und Reichsfinanzminister den eigens geladenen Ministerpräsidenten der Länder unter Beteiligung der ganzen Presse die Lage auseinandersetzten. Dazu haben wir uns im Reichsrat eine sehr gute Plattform geschaffen. Am kommenden Donnerstag wird Schluß-Sitzung des Reichsrates sein. Ende dieser oder Anfang nächster Woche beginnen dann die Kämpfe im Reichstag. Wir haben uns nach sehr langwierigen Kabinettssitzungen doch dazu entschlossen, materielle Vorschläge zu bringen und nicht gleich auf ein Ermächtigungsgesetz loszusteuern. Letzteres hätte zu klar erkennen lassen, daß es der Regierung nur auf Kampf ankam. Jetzt haben wir aber den guten Willen gezeigt, auf materieller Basis mit dem Reichstag einig zu werden. Gelingt es allerdings nicht, dann wird doch der berühmte Artikel 48 verwendet werden müssen. Ob wir dazu den Reichstag auflösen oder nicht, steht noch nicht fest. Persönlich halte ich für diesen Fall die Auflösung nicht für abwendbar. In zwei Wochen werden wir klüger sein.

\section{Donnerstag, den 3. Juli 1930}

Spätabends. Das politische Spiel geht weiter. Heute insofern großer Erfolg für uns, allerdings ein erwarteter, als der Reichsrat mit überwältigender Mehrheit (56: 9 bei einer Stimmenenthaltung) unsere Deckungsvorlage angenommen hat. Zechlin und ich haben gleich ein schwungvolles Communiqué gemacht, um der Sache den nötigen Nachdruck zu verleihen. Zu morgen haben wir die Parteiführer eingeladen und am Montag geht die erste Lesung im Plenum des Reichstages los. Ich glaube im Endeffekt an ein günstiges Ergebnis.

Heute besprach ich alles nochmals mit Dr. Scholz von der Volkspartei. Er schien mir auch schon viel friedfertiger zu sein.

Freitag, den 12. September 1930

Es ist ein Jammer! Wenn die wichtigsten Ereignisse sich zutragen, habe ich so viel zu tun, daß ich nicht dazu komme, Notizen zu machen. Wie soll das besser werden? Es quält mich geradezu, aber ich kann es kaum anders. Heute will ich bloß schnell das mehrere Monate alte und dicke Eis brechen, um es mir auf die Dauer nicht noch schwerer zu machen.

Was hat sich alles inzwischen zugetragen? Der Reichstag ist nun doch aufgelöst 
worden am 18. Juli. Es war schließlich nicht mehr zu verhindern. Ich hatte auch nicht mehr an der Notwendigkeit gezweifelt. Die Reichsregierung hatte sich alle Mühe gegeben, sie noch zu verhindern, um keine Berechtigung für den Vorwurf aufkommen zu lassen, da $\beta$ die Reichsregierung frivol den Artikel 48 verwende und zur Diktatur treiben wolle.

Die große und wichtige Notverordnung kam heraus. Sie brachte mir ungeheure Arbeit. Tag und Nacht mußte ich arbeiten. Daß sie in einer einzigen Verordnung herausgekommen ist, ist wesentlich mein Werk. Durch diesen Schachzug wird ihre spätere Aufhebung erschwert. Der Reichskanzler und ich hatten Verhandlungen mit Herrn Hugenberg und vielen anderen Persönlichkeiten; über die Einzelheiten geben meine vielen Einzeldiktate in den Akten der Reichskanzlei Auskunft ${ }^{144}$.

Nach der Reichstagsauflösung kam die fürchterliche Wahlzeit. Die Sensation war die Auflösung der Rechten. Hugenberg blieb schließlich noch mit 35 Abgeordneten in seiner deutschnationalen Fraktion. Die Splitter auf der Rechten sammelten sich in der Volkskonservativen Partei und dem Landvolk. Aus den Demokraten wurde unter Einbeziehung des Jungdeutschen Ordens die neue Staatspartei ${ }^{145}$ mit Koch-Weser ${ }^{146}$, Mahraun ${ }^{147}$ und Höpker-Aschoff ${ }^{148}$ an der Spitze. Großes Durcheinander im bürgerlichen Lager darüber, daß eine Einigung zwischen Staatspartei und Deutscher Volkspartei nicht zustande kam.

Im Wahlkampf war Reichskanzler Brüning viel unterwegs. Ich begleitete ihn im August zu einer Staatsvisite nach München. Wieder mal ein Tag in einem goldenen Käfig. Alles Nähere brachten die Zeitungen. Dann besuchte ich mit dem Kanzler den Katholikentag in Münster, den ersten, den ich mitmachte. Unvergeßlich! Herrlich die Abendstunden im alten Rathaussaal mit Kerzenbeleuchtung, wo 1648 der Dreißigjährige Krieg beendet wurde. Wir geladenen Gäste trugen uns in das Goldene Buch der Stadt ein. Herrlich dann am folgenden Sonntag der Festgottesdienst im Freien und am Nachmittag die unvergeßliche Rede des Münchener Kardinals von Faulhaber ${ }^{149}$. Ich habe den Text aufgehoben. Der hohe Herr im Kardinalsornat predigte noch, als strömender Regen auf ihn niederprasselte. Alle Fragen der Jetztzeit behandelte er.

144 Zum Beispiel die Aufzeichnungen Pünders vom 12. und 14. Juli 1930 (als Abschrift im Nachlaß, Bd 132) sowie der Vermerk über eine Unterredung Brüning/Dietrich/Hugenberg/ Oberfohren am 17. Juli 1930 (Akten Reichskanzlei, Bd 1870). Zu letzterer vgl. auch O. Schmidt-Hannover, Umdenken oder Anarchie, Göttingen 1959, S. 264.

145 E. Matthias und R. Morsey, Die Deutsche Staatspartei, in: Das Ende der Parteien 1933, Düsseldorf 1960, S. $32 \mathrm{f}$.

146 Erich Koch-Weser, geb. 1875, Jurist und linksliberaler Politiker, Parlamentarier seit 1901, 1913-1919 Oberbürgermeister von Kassel, 1919-1921 Reichsinnenminister, 1928/29 Reichsjustizminister, seit 1924. Vorsitzender der Deutschen Demokratischen Partei.

147 Artur Mahraun, geb. 1890, Gründer (1920) und „Hochmeister" des Jungdeutschen Ordens. Näheres bei K. Hornung, Der Jungdeutsche Orden, Düsseldorf 1958.

148 Dr. Hermann Höpker-Aschoff, geb. 1883, Jurist; seit 1921 Mitglied des preußischen Landtages (Deutsche Demokratisches Partei), seit 1925 preußischer Finanzminister.

149 Michael Kardinal von Faulhaber, geb. 1869, 1910 Bischof von Speyer, seit 1917 Erzbischof von München und Freising. 
Wenige Tage vorher hatte mir der deutsche Botschafter beim Vatikan, Dr. von Bergen ${ }^{150}$, namens des Kardinal-Staatssekretärs Pacelli das Großkreuz des Gregorius-Ordens mit Stern überbracht. Außerordentlich habe ich mich über diese sehr hohe Ehrung gefreut. Massenhafte Glückwünsche erhielt ich zu dieser seltenen Auszeichnung. Verdient habe ich sie wohl nicht, aber ich habe sie doch als Anerkennung meiner vielen Arbeiten um das Konkordat und den deutschen Katholizismus, Kirchenbauten usw. entgegengenommen. Einen Orden übrigens, den man auch tragen darf ${ }^{150 a}$.

Unser alter Familienfreund, Justizminister a.D. Am Zehnhoff ${ }^{151}$, ist kürzlich gestorben. Alte Erinnerungen, nicht zuletzt an meinen lieben Vater, dessen Freund er war, wurden wach. Ferner ist, noch jung an Jahren, Präsident von Olshausen ${ }^{152}$, gestorben, ein schwerer Schlag. Daneben eine erfreuliche Nachricht; Exzellenz Groener hat sich, 62 jährig, nochmals verheiratet; Hochzeit der Ältesten im Hause Curtius.

Noch vor den Wahlen hoffe ich meine Ansichten über das Wahlergebnis niederschreiben zu können. Interessant für hinterher!

\section{Sonntag, den 14. September 1930}

Diese kurzen Zeilen schreibe ich am Wahlsonntag abends, ehe ich noch etwas über das Ergebnis der heutigen Reichstagswahl weiß. Mein Eindruck über das, was jetzt schon geschehen ist und was wir morgen erfahren werden, ist folgender:

Die Wahlbeteiligung wird sich insgesamt nicht unerheblich gegen 1928 steigern, 10 Millionen Nichtwähler werden wir diesmal nicht haben! Die Linke, d. h. Sozialdemokraten und Kommunisten, werden ungefähr gleich stark zurückkehren, d. h. mit etwa $150+50=200$ [Abgeordneten]. Auf der intransigenten Rechten, d. h. Hugenberg-Anhänger + Nationalsozialisten, werden zusammen mindestens 100 Mann antreten, so daß unsere Opposition mehr als 300 Mann stark sein wird. Von den Regierungsparteien wird das Zentrum gewinnen, das bisher 61 Abgordnete hatte, die Staatspartei, die bisherigen Demokraten, werden vielleicht gegenüber ihren bisherigen 25 Mann etwas gewinnen, umgekehrt wird die Volkspartei von

150 Dr. Diego von Bergen, geb. 1872, Berufsdiplomat, seit 1920 Botschafter beim Heiligen Stuhl in Rom.

150a Nach Art. 109 der Reichsverfassung durfte kein Deutscher von einer ausländischen Regierung Titel oder Orden annehmen. Als im Zusammenhang mit den Konkordatsverhandlungen der 20er Jahre von seiten des Heiligen Stuhls die Frage einer Ordensverleihung an deutsche Politiker angeregt wurde, entschlossen sich die Berliner Stellen zu einer stillschweigenden Ausnahmeregelung. Man argumentierte, daß es sich nicht um die Orden einer ausländischen Regierung handele, da der Vatikan zwar souverän sei, aber keinen Staat im üblichen Sinne darstelle. Nach Auskunft Herrn Dr. Pünders hat auch der damalige preuBische Ministerpräsident Braun sich dieser Auffassung bewußt nicht widersetzt.

151 Dr. Hugo Am Zehnhoff, geb. 1855, Jurist und Politiker der Zentrumspartei, Parlamentariex seit 1898, 1919-1927 preuß. Justizminister.

152 Dr. Theodor Olshausen, geb. 1877, Jurist, Präsident des Direktoriums der Reichsversicherungsanstalt für Angestellte. 
bisherigen 45 Abgeordneten etliche abgeben müssen. Die neue republikanische Rechte (Volkskonservative + Landvolk + Christlicher Volksbund ${ }^{153}$ ) werden etwa $10+25+15=50$ Mann stark sein. Letzteres ein mageres Ergebnis. Es hat sich eben gezeigt, daß draußen auf dem Land Hugenberg mit seiner enormen Agitation (Zeitungen, Kino, Flugblätter usw.) noch sehr viel bedeutet. Alles in allem glaube ich also, daß die Regierungsparteien wenigstens 80 Mann weniger stark erscheinen werden als die bisherige Opposition. Wie unter diesen Umständen während des kommenden schweren Winters regiert werden soll, ist vorher schwer zu sagen. Ich bin der Auffassung: Verfassungsänderndes Ermächtigungsgesetz, angenommen von den bisherigen Koalitionsparteien + Sozialdemokraten, d. h. es müßte der eine oder andere Sozialdemokrat in das Kabinett Brüning eintreten. Letzteres habe ich gestern schon mit Staatssekretär Meißner besprochen. Wir haben verabredet, daß der Reichskanzler morgen den Herrn Reichspräsidenten aufsucht. Hindenburg will keinen Rücktritt des Kabinetts und keine große Koalition. Eben habe ich eingehend mit dem Kanzler, der heute nachmittag von einer Wahlrede zurückgekehrt ist, telefoniert. Wir waren einer Meinung.

Nun bin ich gespannt, ob das Ergebnis sehr viel anders sein wird, als ich es eben geschildert habe.

Soeben liest Magda in der Zeitung, daß Exzellenz Dr. Herz, der zehn Jahre Vaters Senatspräsident am Reichsmilitärgericht war, am 9. d. M. verstorben ist. Das geht mir nahe. Mit der Geschichte meines Elternhauses und namentlich mit dem amtlichen Wirken unseres guten Vaters war Exzellenz Herz untrennbar verbunden. Ich werde ihm ein treues Gedenken bewahren.

\section{Dienstag, den 16. September 1930}

Die Sonntagnacht, zu deren Beginn ich obige Zeilen vor Bekanntgabe der Wahlnachrichten niederschrieb, blieb ich allein bis halb $3 \mathrm{Uhr}$ am Radio auf und nahm mit ständig steigender Spannung die Wahlnachrichten auf. Das Ergebnis, dessen Gesamttendenz ich vorstehend richtig geschildet habe, ist noch ungünstiger geworden. Die Wahlbeteiligung ist, wie ich erwartet hatte, außerordentlich stark gewesen, rund $90 \%$, so stark wie noch nie nach dem Umsturz. Das Volk ist eben durch die Sanierungsarbeit des Kabinetts Brüning bis in seine Tiefen aufgerüttelt worden. Das Zentrum hat mit der Bayerischen Volkspartei zusammen sehr gut abgeschnitten, Gewinn von 10 Mandaten. Außer diesem Mittelblock haben nur die beiden extremen Flügel gewonnen, die Kommunisten und die Nationalsozialisten. Erstere haben 75 und letztere die beispiellose Höhe von 107 Mann erreicht. Ein ganz fürchterliches Ergebnis!

Die Sozialdemokraten haben sich nach einem Verlust von 10 Mandaten mit 143 noch leidlich gehalten. Die neue konservative Rechte hat noch etwas schlechter abgeschnitten, als ich oben schätzend niedergeschrieben habe, nämlich nur $43 \mathrm{Ab}$ geordnete. Namentlich die Konservativen des Herrn Treviranus haben miserabel

153 Gemeint ist der „Christlich-Soziale Volksdienst“. 
mit ihren 5 Mann abgeschnitten. Die Deutsche Volkspartei ist von ihren 45 Mann auf 30 Mann herabgerutscht und die neue Staatspartei von 25 auf 20 Abgeordnete.

Die Wahlnachrichten wurden mit größter Bestürzung aufgenommen, im Inund Ausland. Gestern am frühen Morgen rief mich schon Minister Curtius aus Genfan, der natürlich meine Auffassung kennen lernen wollte wegen der großen Rede, die er heute vor dem Völkerbund halten mußte. Gestern vormittag hatten wir dann einekleine Besprechung beim Herrn Reichskanzler, unter Beteiligung derMinister von Guérard, Stegerwald und Treviranus und des Prälaten Kaas. Letzterer flog nachher in $61 / 2$ Stunden nach Genf ${ }^{154}$, hatte dort gestern abend mit Curtius eine Aussprache und befindet sich seit heute nachmittag wieder in Berlin. Moderner Verkehr! Gestern gegen Mittag hatte dann Reichskanzler Brüning Vortrag beim Herrn Reichspräsidenten. Letzterer war frisch und ruhig, erklärte, eine Demission des Kabinetts werde er nicht annehmen. Es solle weiter ruhig und sachlich gearbeitet werden.

Mittags hatte ich zu vierzehn Gedecken zum Frühstück nach dem Kaiserhof eingeladen, anläßlich der Anwesenheit des Gesandten Rauscher aus Warschau. Anwesend noch Minister von Guérard, die Staatssekretäre Weismann, Meißner, von Bülow ${ }^{155}$ und Kempner ${ }^{156}$, Herr von Kauffmann ${ }^{157}$ und verschiedene Herren meines Amtes. Sehr nett und gemütlich.

Heute vormittag hatten wir die erste Ministerbesprechung nach den Wahlen. Ich bin mit dem Herrn Reichskanzler ganz einig. Wir denken uns die Entwicklung folgendermaßen : Eine Sicherung des Sanierungsprogramms in Erweiterung der parlamentarischen Basis des Kabinetts nach links ist leider nicht möglich. Eine Fühlung nach rechts zu den Nationalsozialisten ist für uns natürlich unmöglich, andererseits aber auch eine Bindung mit den Sozialdemokraten ohne die nötigen Sicherungen. Deshalb wird das Kabinett zunächst einmal in bisheriger Zusammensetzung zusammenbleiben, die sachliche Arbeit fortsetzen und die erforderlichen Vorlagen vorbereiten. Diese werden dann an den Reichsrat und Reichstag gebracht, und bei Beginn dieser sachlichen Beratungen wird sich bald zeigen, ob eine sachliche Zusammenarbeit mit den Sozialdemokraten möglich ist. Ich möchte das glauben und hoffen! Ein Ermächtigungsgesetz mit verfassungsändernder Mehrheit ist leider nicht mehr möglich, da Kommunisten und Nationalsozialisten dies verhindern können.

Heute nachmittag hatte ich eine Aussprache über diese Dinge mit Staatssekretär Schäffer. Nächster Tage verhandeln wir mit Dietrich und Stegerwald.

154 Zur Mission Kaas' vgl. auch die Schilderung bei J. Curtius, a. a. O. (vgl. Anm. 5), S. 170, die nach der Auffassung Pünders als übertrieben bezeichnet werden muß.

155 Dr. Bernhard W. von Bülow, geb. 1885, Berufsdiplomat, seit Frühjahr 1930 (als Nach. folger von Schuberts) Staatssekretär im Auswärtigen Amt.

156 Franz Kempner, hervorgegangen aus dem Kolonialdienst, trat 1919 als Regierungsrat in die Reichskanzlei ein und war 1925/26 dort Staatssekretär (Vorgänger Pünders). Im Zusammenhang mit dem 20. Juli 1944, verhaftet und hingerichtet.

157 Heinrich von Kaufmann, geb. 1882, Berufsdiplomat, seit 1928 Dirigent in der Presseabteilung dex Reichsregierung. 
Mittwoch, den 17. September 1930

Wenn ich Zeit habe, komme ich zum Schreiben. Gerade dann, wenn nicht viel passiert ist. So eigentlich auch heute. Ich notiere heute aber doch aus einem besonderen Grunde. Heute nachmittag hatten wir drei Staatssekretäre, Meißner, Weismann und ich, eine sehr eingehende und wichtige Besprechung über die kommende politische Entwicklung. Wir waren völlig einig. Der Niederschlag findet sich in einer vertraulichen Aufzeichnung, die ich heute abend diktiert habe und die ich morgen dem Reichskanzler überreichen werde. Man möge sie später nachlesen in den Akten der Reichskanzlei über die Herbstarbeit der Regierung.

\section{Donnerstag, den 25. September 1930}

Mit großer Sorge sehe ich in die Zukunft, so wie noch nie. Die gegenwärtigen Tage sind kaum vergleichbar mit irgendeiner Zeit nach dem Kriege. Selbst in der Inflationszeit 1923/24, war es insofern besser, als das Volk von dem vorangegangenen Verlust des Vermögens einen starken Druck verspürte, daß nun etwas Durchgreifendes geschehen müsse, während dies heute nicht der Fall ist. Manch einer, der radikal gewählt hat, ist zwar unzufrieden, aber er ist kaum bereit, unter weiteren eigenen Opfern zur Sanierung beizutragen. Jetzt müßte unser Ziel sein, im Parlament eine breite Basis für ein umfassendes Sanierungsprogramm zu schaffen. Reichskanzler Brüning hat am vergangenen Dienstag hierüber bereits ganz geheim mit seinem Amtsvorgänger Müller bei einer Tasse Tee bei Minister Hilferding verhandelt. Auch zwischendurch haben wir teils direkt, teils indirekt unsere Fühler ausgestreckt, aber die Sache ist sehr schwierig. Die Bereitwilligkeit bei den Sozialdemokraten ist sehr gering, und soweit sie vorhanden ist, wird es den Sozialisten kaum möglich sein, wieder ihre Bedingungen zu stellen. Selbst wenn man mit ihnen wieder einig werden würde, würde nach den bisherigen Feststellungen allein diese Tatsache genügen, daß Teile der Regierungskoalition auf der rechten Seite abspringen würden. So hat Minister Schiele bereits dem Reichskanzler erklärt, daß er zur Zeit keine Möglichkeit sehe, mit Sozialdemokraten zusammen im Kabinett zu sitzen. Wenn es nicht funktionieren sollte, so sehe ich nur die eine Möglichkeit, daß wir mit dem gesamten Reformprogramm an den Reichstag gehen und es - wenn er sich versagt - mit Art. 48 in Kraft setzen. Mag der Reichstag dann hinterher sehen, ob er es wieder außer Kraft setzt.

Zunächst ist natürlich Voraussetzung für alles, daß wir ein gutes und solides, wohl durchdachtes Reformprogramm aufstellen. Hieran arbeiten wir jetzt mit fiebernder Eile und Gewissenhaftigkeit. Gestern Nachtsitzung, heute den ganzen Tag von früh bis spät abends wieder Kabinettssitzung. Morgen Fortsetzung und wahrscheinlich wieder eine Nachtsitzung. Dann Schluß am Sonnabend vormittag. Reichsbankpräsident Luther ist dauernd eingeschaltet und arbeitet sehr ordentlich mit, was sehr wichtig ist aus sachlichen, aber auch aus gewissen politischen Gründen.

$\mathrm{Da}$ alles gegenwärtig so unsicher ist, haben wir unseren Einzug in die neue Dienstwohnung verschoben, vielleicht bis 1. 4. 1931. Wer weiß, ob wir dann noch im Amte sind? Aber es ist besser so, als auf einmal auf der Straße zu sitzen. 
Gestern waren wir bei Kollegen Weismann zum Mittagessen eingeladen, zu Ehren des scheidenden russischen Botschafters Krestinski. Vorher war er bei uns in der Reichskanzlei, um sich zu verabschieden. Alles in freundschaftlicher Form, aber doch immer ein eigentümliches Gefühl, mit einem so fanatischen Kommunisten so eng zusammenarbeiten zu müssen. Aber aus Staatsklugheit ist es eben notwendig. Ich sagte noch gestern, daß nach meiner Meinung die Rheinlande noch nicht geräumt wären, wenn wir nicht die engen Beziehungen zu Sowjet-Rußland hätten.

\section{Dienstag, den 30. September 1930}

Sehr arbeitsreiche Tage - und Nächte - liegen hinter uns. Wir haben das Wirtschafts- und Finanzprogramm der Regierung Brüning fertiggestellt. Letzten Sonnabend war es soweit; über Sonntag wurde dann alles sauber zu Papier gebracht und gestern, Montag abend, bis Mitternacht wurde dann alles endgültig verabschiedet. Hierzu hatte ich in der Reichskanzlei alle Beschlüsse genau niederschreiben lassen und dafür gesorgt, daß auch der Entwurf eines Kommuniqués vorlag. Nachdem wir dann heute morgen nochmals in einem kleinen Komitee in der Reichskanzlei zusammengesessen hatten, konnte die Veröffentlichung heute nachmittag erfolgen. Es ist ein riesiges Dokument. Wenn es gelingt, es durchzuführen, ist ein großes Stück Arbeit getan. Aber wird es gelingen?

Wie nun alles politisch geschafft werden soll, weiß heute eigentlich noch so recht niemand. Auch der Kanzler und ich nicht. Eine Ergänzung des Kabinetts durch Eintritt von Sozialdemokraten wird leider unmöglich sein, da es rechts nicht geduldet und von links nicht erbeten wird. Was aber vielleicht möglich wäre, ist eine Unterstützung des Kabinetts und seiner Arbeit durch die Sozialdemokratie. Hierzu hatte ich dem Herr Reichskanzler vorgeschlagen, eine Besprechung mit den beiden sozialdemokratischen Parteiführern Wels und Müller ganz unauffällig bei mir in der Gärtnerstraße von Lichterfelde herbeizuführen. Dr. Brüning war sehr einverstanden, und ich habe dann beide heimlich eingeladen. Wir waren nur zu viert zum Kaffee und nachher zum Glas Wein mit Zigarren. Es war eine zweifellos sehr wertvolle Aussprache ${ }^{158}$. Ich hatte das Gefühl, daß es sich um historische Augenblicke handelt. Meine Frau, die natürlich nicht dabei war, sagte mir eben noch, ich solle die Zusammenkunft nur ja in diesen Blättern festhalten. Nach der heutigen Aussprache scheint es mir tatsächlich nicht ausgeschlossen, daß zur Vermeidung einer Rechtsdiktatur die Sozialdemokratie das Kabinett Brüning unterstützt. Die nächsten Wochen werden das Ergebnis zeigen.

Hitler hat versucht, am vergangenen Sonntag eine Besprechung mit dem Reichskanzler zu haben. Nach Rücksprache mit mir hat Brüning erklären lassen, er sei einstweilen hierzu noch nicht in der Lage, könne aber nächsten Sonntag abend zur Verfügung stehen. Eine schwierige Geschichte, die nicht bekannt werden $\operatorname{darf}^{\mathbf{1 5} 9}$ !

158 Vgl. hierzu die Darstellung bei E. Matthias, Die Sozialdemokratische Partei Deutschlands, in: Das Ende der Parteien 1933, Düsseldorf 1960, S. $105 \mathrm{f}$.

159 Eine gewisse Initiative zu einer Begegnung mit Hitler ist dabei auch von Brüning aus- 
Freitag, den 3. Oktober 1930

Heute vor einem Jahr ist mein großer Freund, der deutsche Staatsmann Gustav Stresemann gestorben. Bei seinem Tode habe ich dieses Tagebuch begonnen. Meine Zuneigung und Verehrung, die schon darin einen wenn auch zufälligen Ausdruck fand, ist noch heute unverändert. Heute haben wir dem Verstorbenen auf dem Luisenstädtischen Friedhof das Denkmal eingeweiht. Ein schlichtes, prächtiges Werk des Professors Lederer. Ich war mit dem Reichskanzler dort. Minister Wirth hielt die Weiherede, nach ihm noch der evangelische Pastor, das Ganze eingerahmt durch Musikstücke. Frau Stresemann mit ihren beiden Söhnen war auch da, ziemlich gefaßt und sehr würdig und sympathisch. Wir drückten uns die Hand.

Der Nachmittagskaffee in meinem bescheidenen Hause in der Gärtnerstraße mit den beiden sozialdemokratischen Führern wird vielleicht noch einmal berühmt werden. Manche Pressenotizen zeigen dies etwas. Die Presse orakelt viel herum, wo die Zusammenkunft wohl gewesen sei!

Inzwischen hat sich nicht viel ereignet. Der Reichskanzler hat die verschiedenen Parteiführer zu sich kommen lassen und ihnen das Regierungsprogramm vorgetragen. Unser Ziel geht zunächst dahin, eine Arbeitsgemeinschaft der Mitte aus den bisherigen Regierungsparteien herzustellen, die immerhin 210 Abgeordnete stark wäre. Die beiden Sozialdemokraten haben wir gestern nochmals in der Reichskanzlei gesprochen. Das Ziel geht dahin, das Mißtrauensvotum der Kommunisten durch einen Antrag auf Übergang zur Tagesordnung totzuschlagen und bei der Notverordnung dem Aufhebungsantrag durch Zulassung von Abänderungsanträgen $\mathrm{zu}$ begegnen, so daß die eigentlichen Schwierigkeiten erst bei der Erledigung unseres Regierungsprogramms beginnen würden. Dementsprechend haben die Sozialdemokraten heute in der ersten Fraktionssitzung einen recht verständigen Beschluß gefaßt, durch den sie sich nicht festlegen. Anders die Wirtschaftspartei, die trotz ihres Charakters als Regierungspartei gestern ganz blödsinnige Dinge beschlossen hat über Revision des Youngplanes, Moratorium, Reichsreform usw. Gestern abend hatte ich eine Besprechung mit Ministerpräsident Braun ${ }^{160}$, der - zwar etwas verklausuliert - der Meinung Ausdruck gab, wer A gesagt habe, müsse auch B sagen, d. h. wer mit der Notverordnung angefangen habe, könne mit diesem Reichstag auch nichts anderes tun, als auf dem Wege fortzufahren. Ich möchte auch glauben, $\mathrm{da} \beta$ es so kommt. Aber nicht im Streit mit dem ganzen Reichstag, nur in stillschweigendem Einvernehmen mit einer Mehrheit könnte die Regierung erneut vom Art. 4.8 Gebrauch machen. Morgen haben wir über diese Dinge eine wichtige Ministerbesprechung, für deren Zweck ich eine sorgfältige Aufstellung über die jetzt zu ergreifenden Maßnahmen gemacht habe bzw. habe machen lassen.

gegangen. Vgl. A. Krebs, Tendenzen und Gestalten der NSDAP, Erinnerungen an die Frühzeit dex Partei, Stuttgart 1959, S. 30 und 140.

160 Dr. Otto Braun, geb. 1872, sozialdemokratischer Politiker, seit 1902 Parlamentarier, 1911 im Parteivorstand der SPD. Seit 1920 (mit zwei geringen Unterbrechungen) preußischer Ministerpräsident. Vgl. auch sein Memoirenwerk: Von Weimar zu Hitler, 2. Aufl., New York 1940 . 
Alles in allem sehe ich nach wie vor mit sehr großer Sorge in die Zukunft, wie noch nie seit 1918. Zwischendurch hatten wir zwei sehr interessante Tage. Die Staatlichen Museen in Berlin feierten ihr 100jähriges Jubiläum, seitdem 1830 Schinkel das Alte Museum am Lustgarten baute und einrichtete. Am ersten Tage ein Festakt in der Aula der Universität mit vielen feierlichen Reden, abends „Rosenkavalier" in der Staatsoper. Herrliche Aufführung und ein farbenprächtiges Bild in den Logen und Rängen. Am zweiten Tage morgens die feierliche Eröffnung des Pergamon-Museums, des Vorderasiatischen und des Deutschen Museums. Wir hatten Glück, indem ihr Baumeister uns gern herumführte, unvergeßlich, namentlich der herrliche Pergamon-Altar. Gestern abend waren wir dann in den „Weißen Saal“ des Berliner Schlosses geladen, wohl das erste Mal seit der Staatsumwälzung, daß diese Räume zu solchen Veranstaltungen gebraucht werden, eine schöne Idee und namentlich eine schöne Synthese zwischen Gegenwart und Vergangenheit, was ich immer so liebe. Die Gegenwart, die Republik, ist so gefestigt, daß sie ohne Kampf gegen die Monarchie deren alte Stätten besuchen darf. Ministerpräsident Braun war der Hausherr; weit über 1000 Gäste, die in den vielen herrlichen Sälen sich verliefen. Das ganze diplomatische Korps mit dem Nuntius an der Spitze! Wir hatten einen sehr netten Tisch mit den Geschwistern Dorpmüller, Exzellenz Boden und verschiedenen Staatssekretären und Universitätsrektoren. Etwas wehmütig war es mir, als ich mir die alten begeisterten Schilderungen des guten toten Vaters vergegenwärtigte, der dort zusammen mit anderen hohen Beamten und Offizieren im Schmucke ihrer Orden vor dem Thron vorbeidefiliert ist! Nun war ich auch einmal dort, aber wie hatten sich die Zeiten geändert, und ich war selbst ein Exponent der neuen Zeit, die auch ihr Gutes hat.

Sonntag, den 5. Oktober 1930

Die politischen Besprechungen haben bis gestern nachmittag ihren Fortgang genommen. Heute am Sonntag abend empfängt der Reichskanzler Brüning die Herren Hitler und Minister Frick ${ }^{\mathbf{1 6 1}}$ von den Nationalsozialisten und morgen vormittag die Deutschnationalen. Die Klärung hebt sich langsam ab, nur steht natürlich noch gar nicht fest, ob es auch so funktioniert, wie man sich die Lösung denken kann. Die Sozialdemokraten haben vorgestern nachmittag in ihrer Fraktion einen sehr staatsmännischen Entschluß gefaßt, der nichts verbaut. Danach kann man hoffen, daß die Sozialdemokraten einen Sturz der Regierung zu verhindern suchen und leidlich mitmachen werden. Die Entscheidungen drängen auch außerordentlich, weil die Kassen- und Devisenkreditlage von Tag zu Tag beängstigender wird. Hoffentlich können wir übermorgen den großen Überbrückungs-Kredit abschließen.

161 Dr. Wilhelm Frick, geb. 1877, Verwaltungsjurist, beteiligte sich 1923 am HitlerPutsch in München, seit 1924 Mitglied des Reichstages (NSDAP), zuletzt Fraktionsvorsitzender. Seit Januar 1930 thüringischer Innen- und Volksbildungsminister. Auf seine späteren hohen staatlichen Funktionen im Dritten Reich soll hier nicht eingegangen werden. 
Dienstag, den 7. Oktober 1930

Die Ehe zwischen Demokraten und Jungdeutschem Orden ist heute wieder auseinandergegangen. 14. Demokraten stehen 6 Volksnationalen gegenüber. Die ganze Gründung der Staatspartei war offenbar eine verfehlte Sache. Hoffentlich finden im neuen Reichstag nun wenigstens unsere Zusammenschlüsse statt: Demokraten + Volkspartei und Volksnationale + Christlich-Nationale.

Heute hatten wir abschließende Kabinettssitzung über Genf. Wie üblich war es aber sehr schwer, Übereinstimmung für ein allseitig gebilligtes Kommuniqué zu finden. Die Billigung stellte man schließlich auf den "Vortrag" des Ministers Curtius ab, dagegen nicht auf die „Haltung“ der Delegation in Genf ${ }^{\mathbf{1 6 2}}$. Feine Unterschiede! Der lächerliche Vorgang zeigt aber, wie gering eigentlich die sachliche Übereinstimmung im Kabinett in diesen überaus wichtigen Fragen ist. Wie das noch werden will, weiß kaum einer.

Die Besprechungen des Reichskanzlers mit den Parteiführern sind heute zu Ende gegangen. Heute abend der bayerische Prälat Leicht, gestern die Deutschnationalen und vorgestern am Sonntag die Nationalsozialisten. Letztere Besprechung war die wichtigste. Sie zeigte a) die allerdings nur grundsätzliche Bereitwilligkeit der Nationalsozialisten zur aktiven Mitarbeit ${ }^{\mathbf{1 6 3}}$, b) aber die gegenwärtige Unmöglichkeit solcher Zusammenarbeit, da nämlich die außenpolitischen Ziele nicht auf einen Nenner zu bringen seien. Die Herren schieden in der Erkenntnis gegenseitiger Hochachtung, zunächst aber absoluter Opposition und mit der entfernten Möglichkeit, nach Scheitern des Kabinetts durch die Haltung der Sozialdemokratie erneut zusammenzukommen, und in der grundsätzlichen Feststellung gemeinsamer Kulturideale. An dieser Besprechung hatte ich nicht teilgenommen, wohl aber an der mit den Deutschnationalen. Erschienen waren die beiden Abgeordneten Oberfohren und Dr. von Winterfeld ${ }^{\mathbf{1 6 4}}$. Sie waren recht friedfertig, es zeigte sich aber, daß sie recht wenig orientiert waren und namentlich keinerlei Verbindung mit den Nationalsozialisten hatten, was aus mehreren Fragen klar hervorging ${ }^{\mathbf{1 6 5}}$.

Übermorgen Donnerstag kommen Reichskanzler Brüning, Bischof Schreiber ${ }^{\mathbf{1 6 6}}$ und noch einige prominente Gäste zu uns. Bischof Schreiber hatte den Wunsch,

162 Vor allem die Minister Treviranus und Schiele hatten zu verstehen gegeben, daß sie das Verhalten der Deutschen Delegation in Genf nicht "billigen" könnten. Protokoll der Ministerbesprechung vom 7. Oktober 1930, Akten Reichskanzlei, Bd 1447.

163 Nach einem Briefe Brünings an K. Frhr. von Hammerstein (Schleicher, Hammerstein und die Machtübernahme 1933, in: Frankf. Hefte 11 [1956], S. 15) hat Hitler (bei dieser oder einer späteren Gelegenheit) das Angebot gemacht, „die NSDAP mit drei Mitgliedern an der Regierung zu beteiligen", was der Reichskanzler entschieden ablehnte.

164 Dr. Friedrich von Winterfeld, Fraktionsvorsitzender der Deutschnationalen Volkspartei im preußischen Landtag, Landesdirektor von Brandenburg.

165 Diese Besprechung wird erwähnt in einer späteren Sammelaufzeichnung Pünders vom 4. Dezember 1930 über die Politik der DNVP. Durchschlag im Nachlaß Schleicher, Bd 17/III (Bundesarchiv Koblenz).

166 Dr. Christian Schreiber, geb. 1872, seit 1921 Bischof von Meißen, seit 1930 Bischof von Berlin. 
einmal mit dem Kanzler am dritten Ort gemütlich zusammenzukommen. Hoffentlich verläuft alles gut. Viel Betrieb.

Freitag, den 10. Oktober 1930

Unsere Gesellschaftsabende liegen wieder hinter uns, einer im Zusammenhang mit einer der üblichen Präsidententagungen im Preußischen Ministerium des Innern. Gestern abend waren der Bischof von Berlin, Dr. Schreiber, der Herr Reichskanzler, der Altreichskanzler Marx, Herr Prälat Leicht und noch verschiedene andere hohe Persönlichkeiten und Prälaten anwesend. Wir hatten es etwas einfacher als sonst gehalten, alles hat bestens geklappt. Der Herr Bischof und der Herr Reichskanzler haben sich besonders gut unterhalten. Der Herr Bischof war mit am Bett unserer drei Kinderchen und gab ihnen seinen Segen.

Politisch ist noch alles recht unklar. Der Überbrückungskredit ist immer noch nicht da. Augenblicklich sind große Schwierigkeiten bei der Deutschen Volkspartei, wo Bestrebungen laut wurden, den Außenminister Curtius aus dem Kabinett zurückzuziehen. Es ist aber noch einmal gut gegangen. Der Reichskanzler und ich empfingen heute nachmittag in der Reichskanzlei nochmals meine "Kaffeegäste“, die sozialdemokratischen Unterhändler Müller und Wels, die diesmal in Begleitung des Fraktionsführers Dr. Breitscheid erschienen. Eine günstige Aussprache! Ich glaube, mit einem Tolerieren seitens der Sozialdemokratie ist zunächst durchaus zu rechnen, so daß Mißtrauensvotum, Aufhebungstendenzen betr. Notverordnung und Überbrückungskredit ganz in unserem Sinne erledigt werden dürften. Dann kann der Reichstag am besten noch einen Monat in die Ferien gehen, um dem Reichsrat Zeit für die Bearbeitung des Sanierungsprogramms zu geben. Am kommenden Montag wird erste Sitzung des Ältestenrats dieses neuen Reichstags sein, wo ich die Pläne der Reichsregierung offiziell vortragen werde.

\section{Mittwoch, den 15. Oktober 1930}

Heute der Vorabend der Regierungserklärung, die morgen von Reichskanzler Brüning abgegeben wird. Den wesentlichsten Anteil an ihrer Fertigstellung habe ich, wie ich in diesem privaten Tagebuch mitteilen darf. Ich stehe in solchen Dingen gern im zweiten Gliede und habe um so mehr Befriedigung, wenn meine Mitarbeit fruchtbar wird. Wir hatten für vorgestern die Beiträge der Ressorts erbeten. Vorgestern abend bis $10 \mathrm{Uhr}$ habe ich dann die Regierungserklärung diktiert, so daß sie gestern in eingehenderMinisterbesprechung beraten werden konnte. Der allgemeineEindruck war, wie ich zu meiner Befriedigung mitteilen kann, sehr gut. Heute morgen hat auch Herr Reichspräsident von Hindenburg zu Staatssekretär Meißner nach genauester Durchsicht gesagt, daß das „wieder mal eine sehr gute Arbeit“ sei. Eigentlich sollten wir heute abend noch eine Ministerbesprechung haben. Da aber das Plenum zu lange dauerte, machen wir sie morgen ganz früh. Hoffentlich liest nun der Kanzler die Erklärung morgen auch gut vor.

Dies war meine Hauptarbeit in den letzten Tagen. Vorgestern war große Aufregung, weil die verehrliche Wirtschaftspartei beschlossen hatte, ihren Minister 
Dr. Bredt ${ }^{\mathbf{1 6 7}}$ aus dem Kabinett herauszuziehen ${ }^{\mathbf{1 6 8}}$. Diesen Zwischenfall haben wir schnell erledigt. Ich verweise auf mein amtliches Pressekommuniqué, wonach Reichspräsident von Hindenburg einen Appell an Minister Bredt gerichtet hat, um zu bleiben. In Wirklichkeit hat der Herr Reichspräsident den Minister überhaupt nicht empfangen. Die ganze Sache haben Meißner und ich hinter den Kulissen besprochen und nach außen so dargestellt. Die Wirkung war fabelhaft; denn es zeigte sich, daß der Reichspräsident nicht gewillt ist, sich von Fraktionsbeschlüssen imponieren zu lassen.

Heute war Reichstagspräsidiumswahl. Sehr dramatisch! Die Nationalsozialisten hatten den Plan ausgeheckt, Herrn Dr. Scholz von der Volkspartei zum Präsidenten zu lancieren, ein törichter Plan, der viel Mißstimmung erregte und schließlich ganz scheiterte.

Das Stimmenverhältnis war 269 Stimmen für Löbe und 209 für Scholz. Als erster gratulierte Scholz sehr ostentativ dem Sieger! Weitere Vizepräsidenten wurden Stöhr von den Nationalsozialisten und die bisherigen Vizepräsidenten Esser und Graef ${ }^{\mathbf{1 6 9}}$. Herr von Kardorff fiel hinten herunter.

\section{Sonntag, den 19. Oktober 1930}

In der Nacht vom Sonnabend zum Sonntag, 1.15 Uhr. Ich komme soeben aus dem Reichstag. Zwar erschöpft, aber alles gut gegangen. Trotz dieses fürchterlichen Reichstages alle vier Punkte gut erledigt: Mißtrauensvotum nicht angenommen. Notverordnung nicht aufgehoben, Schuldentilgungsgesetz angenommen und Reichstag bis zum 3. 12. vertagt. Ein ganz großer Erfolg. Dazwischen das Rededuell von Oldenburg-Reichskanzler ${ }^{170}$.

${ }_{167}$ Dr. Dr. Johann Viktor Bredt, geb. 1879, Professor der Rechte an dex Universität Marburg, Parlamentarier seit 1911. Ursprünglich Anhänger der Freikonservativen, gehörte er später der sog. „Wirtschaftspartei“ (Reichspartei des deutschen Mittelstandes) an. Reichsjustizminister im Kabinett Brüning.

168 Der Führer der Wirtschaftspartei, Drewitz, war in einem Briefe bei Brüning vorstellig geworden, „dem Ergebnis der Wahl vom 14. September durch Umbildung oder Neubildung des Kabinetts" Rechnung zu tragen. Es scheine notwendig, „die Zahl der Ministerien zu verringern und die Vollmachten der im besonderen die Wirtschaft beeinflussenden Ministerien, in der Hand von Fachleuten, zu vergrößern". Zur „Erleichterung" dieser vorgeschlagenen Maßnahmen beschloß die Fraktion der Wirtschaftspartei, ihren Minister Prof. Bredt zu ersuchen, sein Portefeuille zur Verfügung zu stellen, hatte aber nichts gegen einen Wiedereintritt Bredts in ein neugebildetes Kabinett, sofern es „dem Mehrheitswillen des deutschen Volkes in höherem Maße" entspräche und sofern diese Regierung nach den grundlegenden Gesichtspunkten der Wirtschaftspartei vom 26. September und 3. Oktober handeln würde. Schreiben vom 13. Oktober 1930 (Akten Reichskanzlei, Bd 1308).

160 Walter Graef, geb. 1873, Landgerichtsdirektor, Mitglied des Reichstages 1907-1912 und seit 1920 (Deutschnationale Volkspartei). Seit 1925 Vizepräsident des Reichstages.

170 Elard von Oldenburg, geb. 1855, Kammerherr und Rittergutsbesitzer in Januschau/ Westpr., seit dem 14. 9. 30 Reichstagsabgeordneter der DNVP, hatte in der Sitzung einen Vorsto $B$ zugunsten der vom Reichsgericht in Leipzig verurteilten Ulmer Offiziere unternommen und dabei die Reichswehr und ihre Führung scharf angegriffen. Zum Wortlaut der Rede vgl. Oldenburgs „Erinnerungen“, Leipzig 1936, S. $225 \mathrm{ff}$. 
Sonntag, den 26. Oktober 1930

Obige kurze Notizen sind der frische knappe Niederschlag eines tatsächlichen großen Ereignisses. Wider alles Erwarten der Allgemeinheit ist alles so gut gegangen mit dem jungen Reichstag. Ich hatte es allerdings so erwartet und mit Zähigkeit vorbereitet. Daß dies das Ergebnis sein würde, hatte ich in einer Pressekonferenz schon reichlich vorher als Anfang für die künftige Regierungsarbeit mitgeteilt. Diese Sicherheit wirkte natürlich auf die Pressevertreter. Mit diesem ersten guten Ergebnis im neuen Reichstag sind wir natürlich nicht über dem Berg. Die vergangene Woche stand stark unter dem Zeichen des Berliner MetallarbeiterKonfliktes. Vor drei Tagen hatten wir die Metallindustriellen in der Reichskanzlei. Ich hatte dies mit ihrem Geschäftsführer, dem früheren Regierungspräsidenten Brauweiler, vorbereitet. Außer ihm waren die Großindustriellen von Borsig, Köttgen, von Siemens usw. erschienen.

Das Ziel der Regierungsarbeit ist es, entweder ein Schiedsgericht zwischen den beiden Parteien zu vereinbaren, oder aber eine bündige Erklärung der Arbeitgeber, daß die Lohnsenkung erst im neuen Jahre Platz greift. Von dem Regierungsprogramm als solchem, das absolut auf eine Senkung der Selbstkosten, also auch der Löhne usw. ausgeht, kann die Regierung natürlich unter keinen Umständen abgehen. Ich nehme an, daß morgen oder übermorgen die Lösung gefunden wird. Daneben die landwirtschaftliche Notlagel Das Landvolk wollte den Reichstag vorzeitig wieder zusammengerufen wissen, was die Regierung natürlich nicht zulassen kann. Dann kam der Gedanke einer Notverordnung, aber davon kann vorerst keine Rede sein. Jedenfalls haben wir zunächst einmal gestern im Kabinett materiell das Notwendige beschlossen. Die nächste Entwicklung muß zeigen, wie die Dinge erledigt werden sollen. Auch der Haushaltsplan 1931 ist vom Kabinett verabschiedet worden. Nächster Tage kommen all die anderen Gesetze an die Reihe, die zum Wirtschafts- und Finanzprogramm der Regierung gehören. Am 4. November, Dienstag nächster Woche, sollen dann die offiziellen Beratungen mit dem Reichsrat beginnen. Vorher noch einige Besprechungen mit einzelnen Landesregierungen.

Zwei schreckliche Bergwerksunglücke haben sich in dieser Woche zugetragen. In Alsdorf bei Aachen kamen 262 arme Bergknappen ums Leben, und gestern im Saargebiet bei Saarbrücken wieder über 100. Zu traurig! Die armen Leute und noch gar die armen Hinterbliebenen. Man kann gar nicht mehr froh werden.

Der Neubau der Reichskanzlei in der Wilhelmstraße schreitet rüstig seinem Ende entgegen. In einem Monat wird die Behörde umziehen.

Gestern hatte ich ein sehr nettes Frühstück bei Exzellenz Groener zusammen mit Reichskanzler Brüning, Vizekanzler Dietrich, Meißner, Planck ${ }^{\mathbf{1 7 1}}$ und mir.

171 Erwin Planck, Sohn des bekannten Physikers Max Planck, ursprünglich Offizier, während des Ausnahmezustands 1923-24 Rittmeister und Verbindungsoffizier des Reichswehrministeriums zur Reichskanzlei, später Oberregierungsrat in der Reichskanzlei, 1932 Nachfolger Pünders als Staatssekretär unter den Kanzlern Papen und Schleicher. In Verbindung mit dem 20. Juli 1944 verhaftet und im Januar 1945 hingerichtet. 
Anwesend war die gesamte Generalität und Admiralität der Reichswehr ${ }^{172}$. Der Kanzler sprach sehr wirksam.

Mittwoch, den 29. Oktober 1930

Gestern abend spät ist der Metallarbeiterstreik beigelegt worden. Ein sehr großer Erfolg unserer Regierungsarbeit. Die beiden Parteien haben sich auf den Vorschlag der Regierung geeinigt, den Streitfall einem beiderseitigen Schiedsgericht zu unterbreiten, dessen drei Mitglieder die Regierung ernennt und dessen Schiedsspruch unanfechtbar sein wird. Dadurch wird die Frage politisch entgiftet. Persönlich wissen wir, daß der Vorsitzende, für welchen Posten der frühere Reichsarbeitsminster Brauns vorgesehen ist, es im wesentlichen bei dem Schiedsspruch des Schlichters Dr. Völkers bewenden lassen wird, so daß den Notwendigkeiten der Wirtschaft Rechnung getragen wird. Somit haben wir für Anfang Dezember mit keinem Mißtrauensvotum zu rechnen.

Ein wichtiger weiterer Punkt war heute die Tagung des Auswärtigen Ausschusses des Reichstages. Mehrere sehr unangenehme Anträge zur Reparationspolitik von den Rechtsparteien lagen vor. Heute ganz früh hatten Reichskanzler Brüning und ich im Reichstag Einzelbesprechungen mit ziemlich allen Parteivertretern des Ausschusses, um wenigstens eine Vertagung der Anträge zu erzielen. Würden sie nämlich angenommen, so wäre ein Hereinkommen des 500-Millionen-Kredites am 8. November mehr als zweifelhaft geworden. Alles schien gut zu stehen und eine Vertagung mit 16 gegen 12 Stimmen wahrscheinlich. Nach 10 stündiger Debatte sah es heute abend aber doch anders aus. Die Vertagung wurde mit 15 gegen 13 Stimmen abgelehnt. Große Panne! Es drohte jetzt die Annahme der üblen Anträge. Doch nun bekam es eineAnzahl dieser tapferen Volksvertreter selbst mit der Angst und stimmte zum Teil selber gegen ihre Anträge, da sie die Wirkung einer solchen Annahme selbst nicht verantworten wollten. So kam es, da $\beta$ mit wechselnden Mehrheiten schließlich sämtliche Anträge abgelehnt wurden. Ein merkwürdiges Ergebnis! Außenpolitisch wäre es nicht ungünstig gewesen, wenn die Anträge noch in der Schwebe geblieben wären, um gegebenenfalls im Ausland darauf hinweisen zu können. Innenpolitisch ist dieses heutige Abendergebnis aber natürlich ein großer Erfolg der Reichsregierung, die diesem Reichstag wieder einmal ihren Willen aufgezwungen hat. Ein Sieg, den wir - offen gesagt - nicht erstrebt und auch nicht erwartet hatten. Aber man muß halt Mut haben.

Am Sonnabend, dem Allerheiligen-Tage, startet der Reichskanzler mit mir zum Staatsbesuch nach Dresden. Heute war noch ein sehr unangenehmer Punkt, nämlich die Erörterung der bayerischen Postabfindung mit dem Gesandten von Pre-

172 Aus Anlaß einer vom Reichswehrministerium einberufenen Besprechung der Befehlshaber der Gruppen, Wehrkreise usw. Vgl. Th. Vogelsang, Neue Dokumente zur Geschichte der Reichswehr 1930-1933, in: Vjh. Zeitgesch. 2 (1954), besonders S. $400 \mathrm{ff}$. 
ger ${ }^{173}$. Alles Nähere darüber ergibt meine amtliche Aufzeichnung vom heutigen Tage in den Akten der Reichskanzlei ${ }^{174}$.

\section{Freitag, den 31. Oktober 1930}

Gestern haben wir unsere Kabinettsarbeit zum Wirtschafts- und Finanzplan beendet. Wir hatten wieder mal eine Nachtsitzung mit einem eingeschobenen bescheidenen Imbiß. Gegen Mitternacht war die Arbeit fertig.

Heute vormittag hatten wir in der Reichskanzlei die große Aussprache mit den Ministerpräsidenten der acht deutschen Mittelländer, Thüringen, Braunschweig usw., am Nachmittag mit den drei Hansastädten. Letztere Aussprache stand auf einem viel höheren Niveau. Der Hanseatengeist bedeutet gottlob immer noch etwas, auch der Reichsgedanke steht dort im Vordergrund. Einen Streitfall zwischen Minister Wirth und Braunschweig ${ }^{175}$ haben wir beigelegt. Ich hatte Wirth einen Brief geschrieben, worin ich gemä $\beta$ Art. 56 I der Reichsverfassung die Reichskanzlei einschaltete: die Polizeigelder sind ausgezahlt worden. Wirth ist böse auf mich. Morgen nach Dresden.

Montag, den 3. November 1930

Vorgestern am Sonnabend waren wir in Dresden: der Reichskanzler, Minister Dietrich, Ministerialdirektor Zarden, mein Ministerialrat Vogels und ich. Der sächsische Gesandte Dr. Gradnauer begleitete uns. Die Reise ist sehr gut verlaufen. Vormittags bald vier Stunden Verhandlungen im Staatsministerium, dann ein einfaches, aber feines Frühstück im Hotel Bellevue, wozu auch die Spitzen der örtlichen Reichsbehörden eingeladen waren, insbesondere Gen.Lt. von Stülpnagel vom Wehrkreis ${ }^{176}$ und Gen.Lt. Schubert ${ }^{177}$ als Landeskommandant. Dann ein kurzer Spaziergang durch den Zwinger und den Großen Garten. Nachher Teestunde in dem rei-

173 Dr. Konrad von Preger, geb. 1867, Verwaltungsjurist, seit 1919 bayerischer Gesandter in Berlin (beim Reich, Preußen und Sachsen) und Bevollmächtigter zum Reichsrat.

174 Es handelte sich allerdings um mehr als nur um die noch immer ungelöste Frage der „bayerischen Postabfindung". Im Grunde ging es um die Schwierigkeiten, die Bayern und andere Länder dem neuen „Wirtschafts- und Finanzplan“ der Reichsregierung bereiteten, indem man eine "finanzielle Aushöhlung der Länder" befürchtete. Die Besprechung blieb ohne Ergebnis: Aufzeichnung Pünders vom 29. Oktober 1930, Durchschlag im Nachlaß, Bd 134. Zum Gesamtproblem vgl. W. Besson, Württemberg und die deutsche Staatskrise 19281933, Stuttgart 1959, S. $166 \mathrm{f}$.

175 Da gegen den nationalsozialistischen braunschweigischen Innen- und Volksbildungsminister Dr. Franzen ein Strafverfahren wegen Vergehens der Begünstigung eröffnet werden sollte, hatte Reichsinnenminister Dr. Wirth beabsichtigt, sich „die Entscheidung über die weitere Auszahlung des bisher auf Braunschweig entfallenden Anteils an dem Reichsbeitrage für Zwecke polizeilichen Schutzes" zunächst vorzubehalten. Akten Reichskanzlei, Bd 2267.

176 Edwin von Stülpnagel, Generalleutnant, Befehlshaber im Wehrkreis IV (Dresden) und Kommandeur der 4. Division.

177 Generalleutnant Schubert war Artillerieführer IV und Landeskommandant in Sachsen. 
zenden Familiensitz des Ministerpräsidenten Schieck ${ }^{178}$, nach 7 Uhr abends Rückfahrt nach Berlin. Die sächsische Staatsregierung ist eine sehr sympathische Beamtenregierung, die an sich gestürzt ist, aber als geschäftsführendes Ministerium die Geschäfte leitet. Ich kannte - merkwürdigerweise - Dresden noch gar nicht, so daß auch insofern die Reise für mich sehr nett war. Die starke Fühlungnahme mit den Landesregierungen, ein Gedanke von mir, war sicher sehr zweckmäßig. So gut sind die Länder noch nie behandelt worden ${ }^{179}$, hoffentlich wird es seine Wirkung im Reichsrat haben. Besitzen wir erst ein positives Votum des Reichsrates, dann stehen wir dem Reichstag ganz anders gegenüber. Morgen Dienstag beginnt die Reichsratsschlacht. Heute nachmittag fand in der Wohnung des Reichskanzlers zur Vorbereitung noch eine Teestunde zwischen Brüning, Dietrich, Zarden und mir statt.

\section{Sonnabend, den 8. November 1930}

Trotz der Nöte und Schwere der Zeit muß ich sagen, daß wir diese Woche eine "Glücksträhne" gehabt haben. Die Vollsitzung des Reichsrates am Dienstag, die ich inszeniert hatte, war ein Erfolg. Vor den versammelten Staats- und Ministerpräsidenten der Länder und sozusagen der ganzen Öffentlichkeit, dargestellt durch die zahlreichen Pressevertreter, legten Reichskanzler Brüning sowie die Minister Dietrich und Stegerwald den Wirtschafts- und Finanzplan der Reichsregierung dar. Die Wirkung, namentlich der Rede des Kanzlers, war ungeheuer. Seit der Zeit sind nun die Verhandlungen mit dem Reichsrat im Gange. Wir haben mit den Herren fest vereinbart, daß am 20. d. M. die Vollsitzung zur Verabschiedung sämtlicher Vorlagen stattfinden soll. $\mathrm{Ob}$ das ganz genau auf den Tag geraten wird, ist nicht sicher, aber auch gleichgültig. Jedenfalls müssen wir vor dem Zusammentritt des Reichstages am 3. Dezember einige Zeit haben zur Prüfung der Erledigung der Vorlagen im Reichstag. Einstweilen glaube ich, daß die Regierung kurz vor dem Zusammentritt des Reichstages den ganzen Wirtschafts- und Finanzplan durch Notverordnung in Kraft setzen wird. Aber nicht im Kampfe mit dem Reichstag, sondern nach Absprache mit der Mehrheit, die wir auch neulich im Reichstag hatten.

Zwischendurch hatten wir viele Besprechungen über Sonderwünsche einzelner Länder, mit Bayern über die Postabfindung, mit Mecklenburg und Oldenburg über den berühmten $§ 35$ und die Notlage der Landwirtschaft usw. Wir legen Wert auf gute Stimmung der Länder, da die große Mehrheit im Reichsrat für den Wirt-

178 Walther Schieck, geb. 1874, Verwaltungsjurist und der Deutschen Volkspartei nahestehend, 1923 Präsident des Sächsischen Staatsrechnungshofes, seit Mai 1930 sächsischer Ministexpräsident.

179 Zu den damaligen Bestrebungen Brünings und Pünders, die Länder an der Verantwortung für die umfassenden Sanierungsmaßnahmen zu "beteiligen" und die sachliche Diskussion mehr im Reichsrat (dem "Ersatzgesetzgeber") als in dem offensichtlich wenig geeigneten Reichstag stattfinden zu lassen, $\nabla g l$. die ausführlichen Darlegungen bei W. Besson, a. a. O. (vgl. Anm. 174), S. $195 \mathrm{f}$. 
schafts- und Finanzplan natürlich für alle weiteren Entwicklungen von großem Wert ist. Vorher haben wir die ganzen Herrschaften zu Mittwoch abend zum einfachen Abendessen in die Reichskanzlei eingeladen, rd. 120 Gäste, das Gedeck der Not der Zeit entsprechend - zu 5 Mark. Mittags war ein entsprechendes Frühstück in kleinerem Kreise bei Ministerpräsident Braun, an dem auch ich teilgenommen habe.

Außenpolitisch haben wir einem mir vom französischen Botschafter de Margerie empfohlenen Pariser Redakteur Burges [Sonderkorrespondent des Petit Parisien] ein Interview des Reichskanzlers gegeben, das ganz klotzig gewirkt hat ${ }^{\mathbf{1 8 0}}$, aufgesetzt von dem Grafen Saurma in der Presseabteilung. Im Zusammenhang ist zu vermerken, daß das Schiedsgericht im Metallarbeiterstreik seinen Spruch gefällt hat. Vorsitz: der frühere Arbeitsminister Brauns ${ }^{181}$, Beisitzer: Oberbürgermeister Jarres ${ }^{182}$ für die Arbeitgeber und Professor Sinzheimer ${ }^{183}$ für die Arbeitnehmer.

Großer Erfolg: Mit sofortiger Wirkung Senkung um 3\% und ab Anfang Januar die bereits damals vom Schlichter festgesetzten $8 \%$. Politisch ist die Regierung aus der Sache heraus, wenngleich ich in diesen Zeilen vertraulich festlegen kann, daß dieses Ergebnis natürlich von vornherein feststand und sozusagen verabredet war. Aber nun können uns im Reichstag keine politischen Schwierigkeiten gemacht werden, trotzdem ist das, was die Wirtschaft notwendig braucht, durchgesetzt. Ein feiner Streich!

Heute mittag war Oberbürgermeister Adenauer aus Köln ganz allein bei uns zu Tisch. Sehr gemütlich, ein echter Rheinländer und tüchtiger Mann. Er kommt öfters zu mir in die Reichskanzlei und lädt seine Sonderwünsche für Köln gern bei mir ab. Ich brachte ihn nachher zur Bahn an den Zoo.

Gestern Reichskanzler und ich Besprechungen mit Luther über die Wirtschaftslage. Ich deutete ihm nachher an, ob er nicht in das Kabinett eintreten wollte, was er dankend ablehnte. Meine Anregung hatte ihm aber doch sehr gut getan, und er versprach besonders herzlich weitere Mitarbeit vom „Nebengleis“ aus.

\section{Donnerstag, den 13. November 1930}

Die politische Lage erscheint nach wie vor gelockert. Die Verhandlungen im Reichsrat laufen nach wie vor recht gut. Die letzten Entscheidungen stehen jedoch noch aus. Vor drei Tagen hatten Minister Dietrich und ich eine schwere Schlacht im preußischen Staatsministerium, wo wir für die Annahme unserer Vorlagen eintraten. Gestern haben sie ebendort über unseren Haushaltsplan 1931 beraten. Gewisse Schwie-

180 Zum Inhalt vgl. C. Horkenbach, a. a. O. (vgl. Anm. 127), S. 332.

181 Dr. Heinrich Brauns, geb. 1868, Theologe und Jurist, Politiker der Zentrumspartei, seit 1920 Mitglied des Reichstages, 1920-1928 Reichsarbeitsminister.

182 Dr. Karl Jarres, geb. 1874, Jurist und Kommunalpolitiker, Oberbürgermeister von Duisburg, 1923-1925 Reichsinnenminister, Reichspräsidentenkandidat der Rechten im 1. Wahlgang 1925.

${ }_{183}$ Dr. Hugo Sinzheimer, geb. 1875, Professur, Abgeordneter der SPD in der Nationalversammlung, Spezialist für Probleme des Arbeitsrechts. 
rigkeiten sind beim Marine-Etat zu erwarten. Zwischendurch haben die Verhandlungen im Haushalts-Ausschuß über die Notverordnung begonnen. Schließlich wird alles zu einer einzigen großen Entscheidung zusammenwachsen, d. $h$. ob alles dies im Rahmen einer neuen Notverordnung in Kraft gesetzt werden soll. Einstweilen denkt Reichskanzler Brüning daran, diese Entscheidung noch vor dem 3. Dezember vorzunehmen. Aber Sicheres kann man noch nicht sagen.

Schwierig, sehr schwierig ist noch die Frage des Agrarprogramms; die Landwirte und Minister Schiele drängen sehr auf gesonderte und sofortige Erledigung in einer Notverordnung. Gestern abend hierüber Besprechung beim Herrn Reichspräsidenten mit Reichskanzler und Ernährungsminister. Herr von Hindenburg ist sehr ruhig und drängt nicht. Er sieht durchaus ein, daß Brüning sehen muß, seine verschiedenen „Bombons" zusammen auszuteilen, damit das Ganze gerettet wird.

Die Preissenkungsaktion ist in ein neues Stadium getreten. Im letzten Kommuniqué hatte ich das Wort vom „Kabinettsausschuß" gewählt, der gebildet worden sei, um die Arbeit zusammenzufassen. Nun verspricht man sich goldene Berge von unserer Aktion. Heute tagte zum ersten Mal dieser Ausschuß bei uns in der Reichskanzlei, zusammen mit Reichsbankpräsident Luther und [dem preußischen] Handelsminister Schreiber ${ }^{\mathbf{1 8 4}}$. Hoffentlich kommen wir zu leidlichen Ergebnissen. Ich habe fast Angst vor der großen Reklame.

\section{Freitag, den 14. November 1930}

Heute mittag in der Reichskanzlei großes Frühstück zu Ehren des Luxemburger Staatsministers Bech ${ }^{\mathbf{1 8 5}}$, des dortigen Landtagspräsidenten, eines Oberkammerherrn und des hiesigen Geschäftsträgers. Feine gebildete Menschen, die verschiedene wirtschaftliche Dinge hier zu regeln hatten. Näheres bei meinen Dienstakten ${ }^{186}$. Gar mancher würde mich um solche Dinge, Empfänge usw., beneiden. Mir macht es nur Arbeit und raubt mir einen Mittag. Meine wichtigste dienstliche Arbeit war heute die Verlautbarung des Kabinettsausschusses für Preisfragen. Ich glaube, sie ist meinem Ministerialrat Feßler und mir gut geraten. Bin gespannt auf die Wirkung.

Sonnabend, den 15. November 1930

Heute hatten Reichskanzler Brüning und ich eine über zwei Stunden dauernde politische Aussprache mit den drei sozialdemokratischen Unterhändlern Müller, Hilferding und Hertz ${ }^{187}$. Es handelte sich selbstredend um die eben beginnende

184 Dr. Walter Schreiber, geb. 1884, Jurist und liberaler Politiker, seit 1919 bzw. 1921 Mitglied der preußischen Landesversammlung bzw. des Landtages (DDP), seit 1925 preußischer Minister für Handel und Gewerbe.

185 Josef Bech, Jurist, Staatsminister und Präsident der luxemburgischen Regierung seit 1926.

186 Bei dem Besuche Bechs ging es hauptsächlich um Fragen dex Besteuerung und VeräuBerung des Großherzoglich-Luxemburgischen Fideikommißbesitzes in Deutschland. Akten Reichskanzlei, Bd 86.

187 Dr. Paul Hertz, geb. 1888, sozialdemokratischer Politiker, Mitglied des Reichstages seit 1920, Sekretär dex SPD-Fraktion. 
Beratung der Notverordnung und die demnächstige Beratung des Wirtschafts- und Finanzplanes im Reichstag. Die Verhandlungen verliefen an sich sehr harmonisch. Nur sind noch sehr viel Schwierigkeiten. Ich betonte, daß es zweckmäßig wäre, die entscheidenden Punkte der Notverordnung zu den entsprechenden Punkten des Wirtschafts- und Finanzplanes zusammen beraten zu lassen. Ich nehme an, daß es so wohl auch laufen wird. Daß alles zu Ende des Jahres fertig sein soll, wollte nanamentlich Herrn Dr. Hertz noch nicht recht einleuchten. Gestern hat sich Ministerpräsident Braun dem Kanzler gegenüber vernünftiger und entgegenkommender geäußert. Wenn wir bloß mit ihm zu tun hätten, würden wir alles mit Art. 48 machen können ${ }^{188}$. Große Schwierigkeiten macht auch die Frage der agrarischen Maßnahmen, da die Landwirtschaft diese Regelung nach wie vor absolut vorweg genommen sehen will. Heute nachmittag sprach ich hierüber mit Minister Schiele; Dienstag werden wir den Reichslandbund empfangen müssen. Mit dem Kanzler sprach ich heute auch über die allerletzten Möglichkeiten, wo die Verfassungstreue in einer Linie wie ein spitzes Kirchendach verläuft. Wenn der Reichstag unsere etwaigen neuen Notverordnungen aufheben sollte, was dann? Auflösung aber mit neuem Wahlrecht auf Grund einer weiteren Notverordnung und vielleicht auch Hinausschiebung des Wahltermins. Ich bin ziemlich soweit, aber der Reichskanzler - ich muß das hier ihm zu Ehren festhalten - noch nicht. Er würde, glaube ich, lieber vorher doch zurücktreten. Aber wir werden klarer sehen, wenn in einer Woche der Reichsrat den ganzen Wirtschafts- und Finanzplan verabschiedet hat.

\section{Mittwoch, den 19. November 1930}

Heute ist gesetzlicher Feiertag, Bußtag. Fast hätte heute den ganzen Tag der Reichsrat getagt; so blieb er schließlich aber doch frei. Nur heute nachmittag war eine Veranstaltung, an der ich teilgenommen habe: Allerseelen-Gedenkfeier der Katholischen Aktion im Sportpalast. Sehr feierlich und würdig, erfreulicherweise ganz besetzt. Ich war mit Reichskanzler Brüning hingegangen. Erich Klausener gibt sich wirklich mit großem Erfolg redliche Mühe mit unserer Sache. In der Politik geht einstweilen noch alles recht glatt. Der Reichsrat hat vorgestern den Haushaltsplan 1931 nebst den Gesetzentwürfen über die Realsteuersenkung und die Wohnungsgesetze angenommen. Die preußischen Anti-Marine-Anträge ${ }^{\mathbf{1 8 9}}$ wurden abgelehnt. Jetzt steht nur noch das Steuervereinfachungsgesetz und der Finanzausgleich aus, deren Generaldebatte auch bereits stattgefunden hat, Fortsetzung und

$188 \mathrm{Vgl}$. oben S. 63.

189 Dem Reichsetat 1931 war ein Schiffsbauersatzplan der Reichsmarine beigefügt, wonach das Panzerschiff A (Ersatz Preußen) bis 1932 fertig werden sollte (Gesamtkosten 75 Millionen RM); das Panzerschiff B (Ersatz Lothringen) sollte 1931 auf der Marine-Werft begonnen und 1934 fertiggestellt werden (Gesamtkosten 73 Millionen RM). Für 1931 war außerdem die Fertigstellung des Kreuzers Leipzig, für 1932 der Baubeginn des Panzerschiffes C (Ersatz Braunschweig) vorgesehen. Die Anträge der preußischen Regierung im Reichsrat betrafen drastische Kürzungen dieser Marinepositionen im Wehretat. Sie wurden am 17. November mit allen Stimmen gegen die der Antragsteller abgelehnt. 
Schluß nächste Woche bis Donnerstag. Diesen Donnerstag, also morgen, ist Vollsitzung über all die anderen bisher in den Ausschüssen exledigten Gesetze.

Wir werden die Gelegenheit benutzen, um auch etwas Außenpolitisches zu sagen. Die letzte Rede von Tardieu ${ }^{\mathbf{1 9 0}}$ bedarf dringend der Erwiderung, wenn auch zu berücksichtigen ist, daß seine Rede nach Mitternacht und unmittelbar vor einer sehr unsicheren Kammer-Abstimmung gehalten wurde. Die Idee, für diese Entgegnung das morgige Plenum des Reichsrats zu benutzen, stammt von mir, auf die Brüning und Curtius sehr gern eingingen. Wir haben gestern den bayerischen Ministerpräsidenten Dr. Held eine entsprechende Bitte äußern lassen. Morgen vormittag beginnt nun auch endgültig die Beratung der Notverordnung aus dem Sommer; es schien geraten, bis morgen den Haushaltsausschuß mit dieser Arbeit zu verschonen. Nun aber geht es los. Ich habe die Kollegen Joel ${ }^{191}$ und Zweigert ${ }^{192}$ dazugebeten, da vor allem zunächst staatsrechtliche Fragen zur Sprache kommen. Gestern abend war sehr geheim Generaldirektor Vögler ${ }^{193}$ beim Kanzler. Er hat mir als einzigem hinterher den Verlauf des Gespräches erzählt: acht der ersten Bank- und Industriegrößen aus ganz Deutschland hätten gestern acht Stunden lang mit Herrn Hugenberg zusammengesessen, um ihm die ungeheure Schwere der gegenwärtigen wirtschaftlichen Lage auseinanderzusetzen. Wenn weitere Kündigungen ausländischer Kredite erfolgten, sei die völlige Pleite da. Sie müßten daher Hugenberg dringendst ersuchen, unter allen Umständen das Kabinett Brüning zu unterstützen, das auf dem richtigen Wege sei. Er, Vögler, schlage daher vor, Herrn Hugenberg zu bestellen zu einer Rücksprache, zu der er bereit sei. Brüning hat das zugesagt, Hugenberg soll Donnerstag abend kommen. Er sagte aber gleich, daß er die preußische Koalition ihm nicht gleich als Opfer bringen könne. Brüning und ich besprachen dann gestern abend zusammen noch ganz vertraulich die möglichen Entwicklungen, wobei wir uns gegenseitig strengstes Stillschweigen versprachen. Vielleicht käme dann ein Ermächtigungsgesetz von Sozialdemokraten bis Deutschnationalen mit verfassungsändernder Mehrheit zusammen, gegen das dann nur Kommunisten und Nationalsozialisten stimmen würden 194! Der Inhalt dieser Ermäch-

190 Kurze Hinweise auf den Inhalt dieser Rede (vom 19. Oktober) geben Schulthess' Europ. Gesch. Kal. 1930, S. 313 f., und J. Curtius, a. a. O. (vgl. Anm. 5), S. 176.

191 Dx. Carl Walter Joel, geb. 1865, seit 1908 in wichtigen Positionen des Reichsjustizarntes, 1920 Unterstaatssekretär, seit 1922 Staatssekretär im Reichsjustizministerium. 1931 Justizminster im 2. Kabinett Brüning.

192 Erich Zweigert, seit 1923 Staatssekretär und Vertreter des Ministers im Reichsinnenministerium.

193 Dr. Albert Vögler, geb. 1877, Generaldirektor der Vereinigten Stahlwerke, seit 1916 auch Präsident des Vereins Deutscher Eisenhüttenleute. 1919-1924 Mitglied der Nationalversammlung bzw. des Reichstages (Deutsche Volkspartei).

194 Die Besprechung Brüning-Hugenberg kam allerdings erst am 26. November zustande. Angesichts der Absicht des Kanzlers, den Gedanken eines Ermächtigungsgesetzes von SPD bis DNVP (zunächst unverbindlich) zu erörtern, glaubte Hugenberg offensichtlich, daß Brüning ,mit seiner Politik nunmehr endgültig festsitze und absolut auf die deutschnationale $\mathrm{Zu}$ stimmung und Bedingungen angewiesen sei". Die unnachgiebige Haltung Brünings in der Frage der preußischen Koalition führte schließlich zu der Feststellung Hugenbergs, „daß die 
tigung würde dann der mittlerweile vom Reichsrat verabschiedete Wirtschaftsund Finanzplan sein. Außerordentlich bedeutsame Fragen und Entwicklungen, in denen wir augenblicklich stehen.

Die agrarischen Fragen sind auch noch nicht gelöst. Morgen soll nun endlich der Reichslandbund empfangen werden. Um noch etwas Zeit zu gewinnen, habe ich vorgeschlagen, noch den Reichsrat in einer vertraulichen Sitzung einzuschalten.

Donnerstag, den 20. November 1930

Schnell eine Bleistiftnotiz: Heute großer Erfolg. Schlußsitzung im Reichsrat mit Annahme des Wirtschaftsplanes. Spät abends bei von Kardorff.

Sonntag, den 23. November 1930

$\mathrm{Da} ß$ der Abschluß der Reichsratsdebatte am Donnerstag abend für die Regierung ein sehr großer Erfolg war, wird fast nirgends bestritten. Die politischen Erörterungen, wie die Sache nun im Reichstag gehen soll, haben natürlich gleich begonnen. Zu morgen, Montag, habe ich die Sozialdemokraten durch den früheren Reichskanzler Müller gebeten. Die Sozialdemokraten sind, unter Führung des letzteren, augenblicklich sehr verständig. Sie wissen natürlich, daß beim Scheitern des Kabinetts Brüning im Reiche das Fallbeil über die preußische Koalition sofort herabfällt. Die Verhandlungen im Haushaltsausschuß plätschern langsam weiter, ohne daß bisher ein erwähnenswerter Schaden eingetreten wäre. In etwa einer Woche werden wir endgültig klar sehen, ob nicht noch vor dem Zusammentritt des Reichstages am 3. Dezember der ganze Wirtschafts- und Finanzplan im Wege einer neuen Notverordnung in Kraft gesetzt werden muß und wird. Herr Reichspräsident von Hindenburg macht dies mit, wenn Brüning es ihm vorschlagen sollte.

Gestern morgen haben wir lieben Besuch auf dem Anhalter Bahnhof abgeholt, den ungarischen Ministerpräsidenten Graf Bethlen ${ }^{195}$. Letzterer ist der Doyen der europäischen Regierungschefs, seit über zehn Jahren führt er die Geschicke seines Landes. Die Ungarn sind prächtige Leute, ich habe ihre Führung schon oft auf den internationalen Konferenzen beobachten können ${ }^{196}$.

Gestern abend gab der Reichskanzler den hohen Gästen im altehrwürdigen Kongreßsaal der Reichskanzlei ein Festmahl zu 75 Gedecken, nur Herren. Einfach, aber in sehr würdiger Form. Wir saßen nachher im kleinen Kreise mit dem Reichskanzler noch lange und sehr gemütlich zusammen.

Am heutigen Sonntag haben Magda und ich Exzellenz Groener und seiner jungen Frau Gegenbesuch gemacht. Der neue Ehegatte ist gestern 63 Jahre alt geworden, die man ihm allerdings nicht ansieht; seit fünf Jahren war er Witwer.

deutschnationale Opposition nunmehr in noch verstärkterer Form in Erscheinung treten müsse". Signierter Durchschlag einer Aufzeichnung Pünders vom 26. November $1930 \mathrm{im}$ Nachlaß, Bd 136.

195 István (Stephan) Graf Bethlen, geb. 1874, seit 1921 ungarischer Ministerpräsident.

196 Der Durchschlag einer Aufzeichnung des Auswärtigen Amtes über die Besprechung mit Bethlen vom 22. November 1930 befindet sich im Nachlaß Schleicher, Bd 27/C (Bundesarchiv Koblenz). 
Freitag, den 28. November 1930

Unsere Entscheidung steht jetzt unmittelbar bevor. Ich stehe in außerordentlich ereignisreichen Tagen, schrecklich viel Arbeit. Ich habe die feste Überzeugung, daß es in wenigen Tagen zur neuen Notverordnung kommt. Sie wird dreierlei enthalten: Gewisse Änderungen der alten Verordnung hinsichtlich Bürgersteuer, Krankenschein, Arbeitslosenversicherung, sodann die agrarischen Maßnahmen und den Wirtschafts- und Finanzplan ohne den Etat 1931. Der Reichskanzler und ich haben die ganze Woche hindurch dauernd mit Parteiführern verhandelt, so insbesondere auch mit den Sozialdemokraten ${ }^{197}$. Letztere sind nach wie vor recht verständig, aber immerhin ist die Sache doch so, daß eine Erledigung auf dem herkömmlichen Wege unmöglich erscheint. In kleinem Kreise der Staatssekretäre erörterten wir heute die Pläne von Herrn Poetzsch-Heffter ${ }^{198}$. Ministerpräsident Braun hat gestern eine vielbeachtete Rede gehalten, in der er ganz deutlich auf die einzige Möglichkeit der Notverordnung hingewiesen hat.

\section{Dienstag, den 2. Dezember 1930}

Die Würfel sind gefallen! Gestern abend, gegen $8 \mathrm{Uhr}$, hatHerr Reichspräsident von Hindenburg unsere Notverordnung unterzeichnet. Als er in unserer Gegenwart seinen Namen schrieb, sagte er zunächst bedächtig: „Der Herrgott im Himmel möge seinen Segen dazu geben ", und fügte beim letzten Schnörkel aber noch hinzu : „Der Teufel soll aber alle holen, die dagegen anstinken! “

Die letzten Entwicklungen waren folgende: Der Umschwung war so um die Wende vom vergangenen Freitag zum Sonnabend erfolgt. Ab Sonnabend bereiteten wir die einzelnen Teile der Notverordnung vor, eine Besprechung jagte die andere. Die entscheidende Kabinettssitzung hatten wir für Sonntag nachmittag angesetzt. Sie dauerte von 4 Uhr nachmittags bis 3 Uhr nachts! Dazwischen ein bescheidener Imbiß wie üblich in der Reichskanzlei. Schwierigkeiten gab es eigentlich garnicht, bis auf die Agrarwünsche des Herrn Ministers Schiele, der plötzlich allerlei neue Dinge reinmogeln wollte, was natürlich abgelehnt wurde. Am gestrigen Montag wurde die Notverordnung auf Grund der Kabinettsbeschlüsse formell zusammengestellt; diese Arbeit leistete mustergültig mein Kollege Zweigert als zuständiger Staatssekretär des Reichsministerums des Innern, mit Unterstützung meiner Mitarbeiter von Hagenow und Vogels. Die fleißigen Leute haben in dieser Nacht wieder bis 3 Uhr nachts gearbeitet. Der Erfolg besteht aber auch darin, daß das

197 Die genannten Veränderungen der alten Notverordnung erfolgten im wesentlichen in der Form, wie sie seitens der sozialdemokratischen Gesprächspartner Breitscheid, Hertz und Hilferding erbeten worden waren. Durchschlag einer Aktennotiz Pünders vom 29. November 1930 im NachlaB, Bd 136.

198 Dr. Fritz Poetzsch-Heffter, geb. 1881, sächsischer Ministerialdirektor und stellvertretender Bevollmächtigter zum Reichsrat. - Die "Pläne" Poetzsch-Heffters bezogen sich auf eine sog. "Deflationsgesetzgebung" und standen in Zusammenhang mit dem von der Reichsregierung geplanten Ausgabensenkungsgesetz. Schreiben des Staatssekretärs Zweigert an Pünder vom 26. November 1930, Akten Reichskanzlei, Bd 1870. 
90 Seiten starke Gesetzgebungsbuch bereits heute früh dem Reichstagspräsidenten zur Verteilung im Reichstag vorlag! Eine geradezu bewundernswerte Leistung unserer so viel geschmähten Bürokratie. Am gestrigen Tage saß dann Reichskanzler Brüning noch einer Reichsratssitzung vor, wo er die Länder über die Kabinettsbeschlüsse orientierte. Schwierigkeiten gab es noch erheblich mit den Bayern, die vier Mann hoch bei uns antraten: Ministerpräsident Held, Parteiführer Schäffer ${ }^{199}$, Prälat Leicht und Reichsminister Schätzel. Sie wollten noch gegen die Steuervereinfachungsbestimmungen Sturm laufen und drohten mit politischen Schwierigkeiten ${ }^{200}$, was aber auf Brüning, Dietrich, Zarden und mich, die wir die Gegenseite vertraten, keinerlei Eindruck machte. Geändert wurde nichts mehr.

Nachmittags 5 Uhr fand dann der Vortrag des Reichskanzlers beim Herrn Reichspräsidenten statt, der sehr glatt und friedlich verlief. Fortsetzung siehe oben!

Heute morgen erschien der bisher erkrankte Justizminister Bredt wieder bei uns. Die Behandlung seines Rücktrittsgesuches ist aber noch zweifelhaft. Vielleicht gelingt es, noch dieFassade zu wahren ${ }^{201}$. Auch Minister Schiele schrieb dem Reichskanzler wieder einen Brief, wo er mit Rücktrittsabsichten drohte. Ich antwortete in einem Brief an Herrn Heukamp, meinen Kollegen im Ernährungsministerium ${ }^{202}$. Beinahe hätte es gestern auch noch Schwierigkeiten mit Herrn Schätzel gegeben. Wenn die Öffentlichkeit wüßte, wie bröckelig in Wirklichkeit die Fassade dieses Kabinetts ist! Drei Minister nur halb bei der Sache. Aber wir bemühen uns, die Fassade in Ordnung zu halten. Das ist die Hauptsache. Hinter dieser Fassade entwickelt sich die alles beherrschendeEnergie des Reichskanzlers Brüning, der seit langer Zeit wieder mal ein leitender Staatsmann in des Wortes edelster Bedeutung ist.

Noch eine wichtige Begebenheit muß ich eintragen: Am vergangenen Mittwoch besprachen sich Reichskanzler Brüning, meine Wenigkeit, Ministerpräsident Braun und Zentrumsführer Dr. Heß über die politische Lage. Braun gab sehr beruhigende

199 Dr. Fritz Schäffer, geb. 1888, Politiker der Bayerischen Volkspartei, seit 1920 Mitglied des bayerischen Landtages, seit 1929 Vorsitzender der BVP, seit 1931 Staatsrat und Leiter des bayerischen Finanzministeriums (bis 1933).

200 Die bayerische Staatsregierung hat acht Wochen später, am 30. Januar 1931, wegen $\operatorname{der}$ Aufnahme des sog. Steuervereinfachungsgesetzes in die Notverordnung vom 1. Dezember 1930 Klage beim Staatsgerichtshof in Leipzig erhoben. Sie sah darin einen Eingriff in die Lebensrechte der Länder, zumal - nach ihrer Auffassung - „dieses Gesetz durch die Zeitverhältnisse und die Finanz- und Wirtschaftsnot des Deutschen Reiches in keiner Weise veranlaßt war". Akten Reichskanzlei, Bd 2226.

201 Die Wirtschaftspartei, welcher Bredt angehörte, erlebte seit Anfang November erneute innere Auseinandersetzungen und hatte „ihren“ Minister veranlaßt, dem Kabinett endgültig den Rücken zu kehren. Vgl. dazu eine Formulierung aus dem Beschluß des Reichsausschusses dieser Partei: „Die Ereignisse der letzten Zeit bewiesen aber, daß die Reichsregierung Brüning ihre Politik in Anlehnung an die Sozialdemokratie unter Preisgabe lebenswichtiger Interessen des deutschen Volkes und der deutschen Wirtschaft durchzuführen versucht." Augsburger Postzeitung vom 26. November 1930.

202 Entwurf im Nachlaß Pünder, Bd 134. In diesem Schreiben wird allerdings mehr die Plötzlichkeit der wie „Feuerüberfälle“ wirkenden, im Kabinett zu später Nachtstunde vorgetragenen neuen agrarpolitischen Anträge (vgl. oben S. 77) in aller Freundschaftlichkeit gerügt. 
Erklärungen ab. Näheres darüber habe ich in einer amtlichen Aufzeichnung niedergelegt. Danach war eigentlich die Entscheidung klar: Notverordnung ${ }^{203}$.

\section{Donnerstag, den 4. Dezember 1930}

Heute war der zweite Tag der großen politischen Aussprache im Reichstag. Bisher gestern und heute sehr ruhig, beinahe langweilig. Eingeleitet gestern durch eine große Etatrede des Finanzministers. Brüning wollte heute während der Debatte reden. Es war aber nicht nötig, vielleicht morgen. Die politischen Schwierigkeiten haben sich jedoch als erheblicher herausgestellt als zuerst angenommen. Die Wirtschaftspartei und die Landvolkpartei stimmen ziemlich sicher gegen die Regierung, wie allerdings anzunehmen war. Aber auch bei den Christlich-Nationalen und der Bayerischen Volkspartei ist noch nicht alles glatt. Mit letzterer hatten wir heute wieder mal eine lange Besprechung über das Steuervereinfachungsgesetz, anscheinend mit Erfolg. Auf wie lange? Jetzt kommen die Gastwirte und wollen wieder Brötchen in den Gastwirtschaften feihalten dürfen, sonst machen sie nicht mit usw. An sich ist geplant, daß bis Sonnabend der ganze Spuk vorbei ist. Zeitlich wird es wohl sicher geraten, hoffentlich auch mit dem Erfolg, der nötig. Das Gegenteil wäre geradezu grauenhaft. Über die möglich en Folgen sprach ich heute ganz vertraulich mit Exzellenz Groener unter vier Augen. Reichstagsauflösung und Nichtwiederwahl? Groener ist dafür und sagt, nur Reichskanzler Brüning könne das machen. Reichspräsident von Hindenburg werde sicher mitmachen. General von Hammerstein ${ }^{204}$ sei für alle Fälle ein ganz vortrefflicher Inhaber der vollziehenden Gewalt. Nicht zuletzt deswegen habe er ihn auch gerade ausgesucht, besser als General von Stülpnagel ${ }^{205}$, was ich durchaus bestätigen muß. Hoffentlich bleiben aber solche Gespräche Theorie. Einstweilen hoffe ich auf den Erfolg. Spitz gerechnet sind für die Regierung 307 Abgeordnete und 270 dagegen. Auf beiden Seiten werden einige fehlen, so da $B$ ich immerhin mit einer geringen, aber doch recht sicheren Mehrheit von 25 bis 35 Stimmen rechne.

\section{Montag, den 8. Dezember 1930}

In vorstehender Prophezeiung habe ich recht behalten. Vorgestern, Sonnabend, hat die Regierung im Reichstag gesiegt, und zwar bei der entscheidenden Abstimmung mit einer Mehrheit von 38 Stimmen. Die Größe der Mehrheit ist diesmal - wie ich dauernd betone - an sich ganz gleichgültig. Denn wir wollen ja gar

203 Laut Aktennotiz vom selben Tage (Nachlaß Pünder, Bd 136) fand die Besprechung mit Braun und $\mathrm{He} 3$ am Sonnabend, den 29. November, statt.

204 Kurt Frhr. von Hammerstein-Equord, geb. 1878, General der Infanterie, aus dem Generalstab hervorgegangen, 1929 Chef des Truppenamtes, seit 1. Dezember 1930 Chef der Heeresleitung.

205 Joachim von Stülpnagel (vgl. Anm. 90). Stülpnagel hatte ursprünglich - auch in den Augen Groeners - als designierter Nachfolger des Generalobersten Heye im Amt des Chefs der Heeresleitung gegolten. Die schließliche Ernennung Hammersteins ging zum größten Teil auf das Betreiben Schleichers zurück. 
nicht mit dem arbeitsunfähigen Reichstag arbeiten, sondern verlangen nur, daß er der Regierung nicht in den Arm fällt. Ob er nun letzteres mit viel oder wenig Stimmen ablehnt, ist gleichgültig.

Der Sieg ist eine große Erleichterung und seelische Entspannung. Aber wie es so istl Wenn eine solche Spannung überwunden ist, dann wird von ihr nicht mehr gesprochen, sondern neue Schwierigkeiten stehen sofort wieder im Vordergrund. Diese sind diesmal allerdings reichlich vorhanden. Der Reichstag ist nämlich noch nicht vertagt. Vorgestern habe ich mich dafür bemüht, vor allem in Gesprächen mit dem früheren Reichskanzler Müller, sich für eine sofortige Vertagung bis Anfang Februar einzusetzen. Das wäre zweifellos für unsere ganze Wirtschaft das Beste gewesen. Es war aber nicht zu erreichen. Nun droht infolgedessen ab Mittwoch dieser Woche eine ganz große außenpolitische Debatte mit allen möglichen Wechselfällen.

Hierzu zähle ich vor allem ein sicher zu erwartendes Mißtrauensvotum gegen Minister Curtius. So wie die Stimmung im Reichstag ist, ist seine Annahme nicht ganz unwahrscheinlich. Was kommt dann? Sicher der Rücktritt des Ministers Curtius, vielleicht auch der des ganzen Kabinetts. Brüning würde dann natürlich wieder neu betraut, aber neue Erschütterungen wären sicher die Folge. Heute besuchte mich der General von Schleicher, um mit mir die möglichen Entwicklungen zu besprechen: Reichskanzler Brüning zugleich Außenminister und Wehrminister Groener (anstelle des nach seiner Meinung gleichfalls überfälligen Ministers Wirth) zugleich Innenminister. Selbst wenn jetzt diese Personalschwierigkeiten überwunden werden, im neuen Jahr, spätestens Anfang Februar, sind sie akut. Wenn die beiden Minister ausscheiden müssen, wäre mir die vorgenannte Lösung die sympathischste ${ }^{\mathbf{2 0 6}}$. Das Problem der Nationalsozialisten spielt dabei natürlich auch hinein. Am Sonnabend besprachen ganz geheim Reichskanzler Brüning, Staatssekretär Meißner, Prälat Kaas und ich diese Dinge.

Zu gestern abend hatten wir den Herrn Reichskanzler, Herm Prälaten Kreuz, den Präsidenten des Deutschen Caritasverbandes, Herrn Professor Muckermann 207 und nahe Verwandte eingeladen. Es war wunderbar! Eine einfache gemütliche Gastfreundschaft und eine außerordentlich hochstehende Unterhaltung. Kreuz und Muckermann sind ja sozusagen die Verkörperung zweier Weltanschauungen im gleichen katholischen Lager. Kreuz tritt für die Schwachen und Kranken ein, während Muckermann als der moderne Apostel der Eugenik und Rassenkunde das übertrieben findet und für starke Förderung der erbgesunden Familien eintritt. Herrliche Synthesen brachten wir zusammen. Brüning äußerst interessiert und entspannt.

206 Bekanntlich ist diese von Schleicher schon jetzt vorgeschlagene Ressortverteilung ein knappes Jahr später bei der Bildung des zweiten Kabinetts Brüning Anfang Oktober 1931 tatsächlich verwirktlicht worden.

207 Dr. Hermann Muckermann, geb. 1877, katholischer Priester und Professor am KaiserWilhelm-Institut für Anthropologie, menschliche Erblehre und Eugenik in Berlin-Dahlem. 
Sonntag, den 14. Dezember 1930

In dieser vergangenen Woche ist schließlich doch wieder alles nach Wunsch gegangen. Vorgestern Freitag nachmittag hat sich der Reichstag auf unseren Wunsch, den man aber nicht zu deutlich aussprechen durfte, vertagt, und zwar auf den weiten - von uns erbetenen - Termin vom 3. Februar 1931. Am Dienstag abend war die gefährliche Geschäftsordnungsdebatte, wo darüber entschieden wurde, ob noch eine außenpolitische Debatte sein sollte. Auch diese Anträge wurden abgelehnt, damit auch die Mißtrauensanträge gegen die Minister Curtius, Wirth und Treviranus einstweilen illusorisch gemacht. Mit diesem Reichstag ist eben nur so $\mathrm{zu}$ arbeiten, daß die Regierung mit Art. 48 arbeitet, dann die verfassungsmäßige Debatte über Aufhebungsmöglichkeit stattfindet, und nach deren Erledigung das hohe Haus wieder verschwinden muß. Ich möchte es nicht für unmöglich halten, daß auf diese Weise noch eine längere Zeit regiert werden kann. Ähnlich schrieb auch gestern der Vorwärts in bemerkenswerter Weise. Aber Anfang Februar wird es gewiß sehr hoch hergehen. Ich habe das festeEmpfinden, daß dann zum mindesten das Kabinett umgebildet werden müßte. Doch ein Kabinett Brüning muß es bleiben, da der gegenwärtige Reichskanzler wohl unstreitig augenblicklich und in der nächsten Zukunft der wohl einzig mögliche Reichskanzler ist und sein wird.

Vor einigen Tagen sah ich mit Magda die Regierungsaufführung des Filmes „Im Westen nichts Neues" an. Erschütternd und doch wahr. Trotzdem bin ich letzten Endes doch auch für Verbot des Filmes. Denn Ruhe und Ordnung würden durch seine Aufführungen gestört, außerdem soll in Amerika ein längerer Film laufen, in dem sich angeblich deutschhetzerische Teile befinden. Einige Teile in ihrer starken Hervorhebung wirken entgegen der Wirklichkeit geradezu typisierend und erwecken dadurch einseitige Eindrücke. Jetzt ist er verboten, und das Feuer der Erregung muß erst ausbrennen.

Jetzt steht uns noch eine sehr arbeitsreiche Woche vor Weihnachten bevor, da viele Arbeit durch den blöden Reichstag liegen geblieben ist: Abrüstung ${ }^{208}$, Preissenkung und viele Kabinettssachen.

\section{Donnerstag, den 18. Dezember 1930}

Nur wenige Zeilen! Unser Gesandter Rauscher in Warschau ist heute nacht gestorben. An Kehlkopfkrebs oder-tuberkulose. Ich habe ihn gut gekannt. Ich werde ihm die Treue bewahren. Eine umstrittene Persönlichkeit wegen seiner Polenpolitik und als November-Sozialist.

208 Im Bereiche des „Abrüstungs"-Problems stand damals der gerade zustandegekommene sog. "Abkommens-“ oder „Konventions-Entwurf" der Vorbereitenden Abrüstungskommission im Vordergrunde der Betrachtung und - Kritik. Die Reichsregierung hatte dem Entwurf, der auf der großen Genfer Abrüstungskonferenz von 1932 beraten werden sollte, vor allem deswegen ihre Zustimmung versagt, weil der Artikel 53 ausdrücklich die weitere Gültigkeit der Versailler Entwaffnungsbestimmungen als Bestandteil allgemeiner Abrüstungsbestrebungen guthie $B$ und damit die deutsche Forderung nach gleicher Behandlung aller beteiligten Staaten von vornherein nicht anerkannte. 
In der französischen Kammer ist das neue Kabinett Steeg mit einer Mehrheit von nur 7 Stimmen soeben zum Siege gekommen! Heute wichtige Besprechung mitReichsgerichtspräsidentBumke wegen Beilegung des Polizeikonfliktes mit Thüringen ${ }^{209}$. Diese letzten Tage vor Weihnachten sind gräßlich. Ich komme bald nicht mehr durch. Jeder will noch schnell seine Sachen erledigen.

\section{Sonntag, den 21. Dezember 1930}

Die Besprechungen mit Reichsgerichtspräsident Bumke sind zunächst zu einem guten Ende geführt worden. Zweigert und ich haben einen Vergleichsvorschlag gemacht, der mit ganz kleinen Abänderungen von Thüringen angenommen worden ist. Hatte dieserhalb mit Herrn Bumke abermals ein langes Telefongespräch aus Weimar. Wir haben dann verabredet, da $\beta$ morgen, Montag, 12 Uhr mittags der Vergleich formell zum Abschluß gebracht werden soll, im Reichsgerichtsgebäude. Zum ersten Mal, daß ich das Reichsgericht besuche, und zwar in solcher Mission! Die Unterhändler des Reiches sind Wirth, Zweigert und ich. Die Beilegung ist deshalb so wichtig, weil das Reich den Prozeß wahrscheinlich verlieren würde und damit die Nationalsozialisten einen Stempel für ihre Legalität erhalten hätten, und zwar vom höchsten Gericht Deutschlands. Der Prozeß war wirklich eine Torheit erster Klasse ${ }^{\mathbf{2 1 0}}$.

In diesen Blättern muß ich festhalten, daß ab morgen die Reichskanzlei im neuen Dienstgebäude nebenan ihre Arbeit verrichten wird. Eine offizielle Feier möchten der Reichskanzler und ich nicht veranstalten wegen der Not der Zeit. Vielleicht gelegentlich der 60-Jahr-Feier des Reiches am 18. Januar 1931. Zunächst werde ich zwischen den Feiertagen eine Presseführung veranstalten.

Gestern abend war ich sehr gemütlich und ganz privat mitMinister Treviranus und Köpke bei Herrn und Frau Gesandten Exzellenz Frank ${ }^{\mathbf{2 1 1}}$ eingeladen; hinterher habe

209 Neben anderen Streitpunkten, die seit 1929 zwischen Thüringen und dem Reich bestanden, hatte im Mai 1930 Reichsinnenminister Wirth die Berufung von Nationalsozialisten auf führende Posten der thüringischen Polizei durch Innenminister Frick zum Anlaß genommen, die Reichszuschüsse für Polizeizwecke an Thüringen zu sperren. Das Reich und auch die meisten Länder vertraten die Ansicht, daß die NSDAP verfassungsfeindlich sei und da $\beta$ die Ernennungen den Grundsätzen für die Gewährung dieser Reichszuschüsse zuwiderliefen. Bemühungen der thüringischen Staatsregierung um eine einstweilige Verfügung des Staatsgerichtshofes waren erfolglos geblieben.

210 Aus dem Vergleichsvorschlag vom 22. Dezember 1930: „.. Die Parteien sind sich darüber einig, daß die Frage, ob und inwieweit die NSDAP umstürzlerische oder sonst strafbare Ziele verfolgt, im Rahmen des gegenwärtigen Verfahrens nicht ausgetragen werden kann und soll ... Die Parteien gehen davon aus, daß die grundsätzliche Frage demnächst in einem anderen vor dem Reichsgericht schwebenden Verfahren einer Klärung zugeführt werden wird. Das Reich hebt die Sperrung der Polizeizuschüsse auf; die bisher einbehaltenen Beträge werden nachgezahlt. Das Land Thüringen nimmt seinen Antrag vor dem Staatsgerichtshof zurück ... und erkennt wiederholt die Verpflichtung an, dafür Sorge zu tragen, daß der unpolitische Charakter der Schutzpolizei als Ganzes wie auch das unpolitische Verhalten des einzelnen Beamten im Dienst unbedingt gewährleistet wird ..." Akten Reichskanzlei, Bd 2316.

211 Dr. Felix Frank, geb. 1876, Jurist und Politiker, 1922-1924 österreichischer Vizekanzler, seit 1925 a. o. Gesandter und bevollmächtigter Minister der Republik Österreich in Berlin. 
ich noch bis $1 / 2$ Uhr nachts in meinem alten Dienstzimmer gearbeitet und dann dort Abschied genommen. Etwas wehmütig! Ab 1. Januar wird nun dort Herr Minister Treviranus als [Leiter der] Oststelle einziehen.

\section{Mittwoch, den 24. Dezember 1930}

Vorgestern war ich in Leipzig im Reichsgericht. An der Vergleichssitzung nahmen teil Reichsgerichtspräsident Bumke als Vorsitzender, von uns: Reichsminister Wirth, Staatssekretär Zweigert mit Ministerialdirektor Menzel und ich, von Thüringen: der leitende Staatsminister Baum ${ }^{\mathbf{2 1 2}}$ mit meinem Regimentskameraden Ministerialrat Guyet, der in Weimar Leiter der Polizeiabteilung ist. Zeitweilig stand alles etwas kritisch, nachher einigten wir uns aber doch auf den Vergleichsvorschlag Bumkes, den in Wirklichkeit Zweigert und ich vorher entworfen hatten! Schwierigkeiten machte noch eine Personalfrage wegen der schwebenden Disziplinarverfahren, wo sich Herr Menzel und sein Mitarbeiter Häntzschel ${ }^{213}$ auch nachher noch wieder mal unglaublich benommen haben. Die Einzelheiten sind so ärgerlich, $\mathrm{da} B$ ich sie gar nicht mal niederschreiben will.

Gestern und heute waren dann noch sehr betriebsame Tage, besonders erschwert dadurch, da $\beta$ wir gerade in das neue Gebäude eingezogen sind; es macht sich aber langsam alles und gut. Der Bau ist auch technisch ganz großartig konstruiert. Heute führte ich Herrn Dr. Osborn und meinen Vorgänger Kempner durch die Räume, die beide begeistert waren.

Reichskanzler Brüning dankte mir reizend für alle ihm im vergangenen Jahr geleistete Arbeit und sprach die freudige Hoffnung auf ebensolche Zusammenarbeit im neuen Jahre aus, das zweifellos sehr schwer werden wird. Zunächst wird Herr Brüning einige Tage nach Badenweiler fahren und bald darauf für eine Woche in den deutschen Osten. An sich wäre ich gern mitgefahren, ich bin aber sehr ruhebedürftig und ganz froh, dann hoffentlich etwas ruhige Tage zu haben.

\section{Montag, den 29. Dezember 1930}

Reiches harmonisches Weihnachtsfest, in Gesundheit und Frohsinn verlebt im Kreise der engeren und weiteren Familie. Gestern abend spät ist Brüning für eine Woche nach Badenweiler auf Urlaub gefahren. Vielleicht habe ich jetzt bald mal etwas Ruhe. Ich kann sie dringend brauchen. Ich bin recht herunter. Heute morgen bei Sanitätsrat Skutsch großes Unglück durch Entzünden eines Benzinfünkchens. Ich fast wie durch ein Wunder völlig unversehrt geblieben. Magda und ich haben dem armen Sanitätsrat mächtig geholfen; ohne uns lebte er wahrscheinlich nicht mehr. Brachten ihn ins Stubenrauch-Krankenhaus, wo er jetzt liegt. In der Presse schon große Aufregung dieserhalb.

212 Erwin Baum, geb. 1868, Landwirt und Agrarpolitiker, Mitglied der Christlich-Nationalen Bauern- und Landvolkpartei. Seit 1920 Mitglied des thüringischen Landtags, seit Januar 1930 thüringischer Staatsminister.

${ }^{213}$ Dr. Kurt Häntzschel, geb. 1889, Verwaltungsjurist, seit 1929 Ministerialdirigent und Leiter der Unterabteilung I A (für Politik) im Reichsinnenministerium. 
Dienstag, den 30. Dezember 1930

Heute ein schöner Erfolg! Großer Empfang der Presse in der neuen Reichskanzlei durch mich. Das Echo daraufhin durchweg ganz ausgezeichnet. Nachmittags Rundfunkreportage von Dr. Osborn im Neubau. Hierbei sprach auch ich erstmalig im Rundfunk. Wie ich hörte, mit bestem Erfolg. Herrn Dr. Skutsch scheint es trotz schwerer Brandwunden leidlich zu gehen.

\section{Mittwoch, den 31. Dezember 1930}

Eigentlich habe ich heute nicht viel mitzuteilen. Aber ich habe eben nachgelesen, $\mathrm{da} \beta$ und was ich heute vor einem Jahr am Silvesterabend niedergeschrieben habe, und sehe daraus, daß an solchen Zeitabschnitten auch die Mitteilung zunächst belanglos scheinender Vorkommnisse hinterher lesenswert erscheint. Darum! Gottlob habe ich ich seit drei Tagen etwas Ruhe, zumal mein verehrter Chef in Badenweiler weilt. Täglich telefoniere ich mit ihm; heute sandte ich ihm ein Telegramm namens der Reichskanzlei. Die Wünsche kamen mir und allen Angehörigen der Reichskanzlei diesem Manne gegenüber wirklich vom Herzen. Der gestrige Tag mit derFührung der Presse durch die neue Reichskanzleiund nachmittags mein Rundfunkdebut war offensichtlich ein schöner Erfolg. Das Echo der Presse zum Neubau ist durchweg sehr gut, entgegen allen miesmachenden Angstmachern. Heute morgen empfing ich den neuen russischen Botschafter Chintschuk ${ }^{214}$. Ich habe ihn jetzt schon mehrfach gesprochen. Er gefällt mir recht gut, besser als sein undurchsichtiger Vorgänger. Er ist offenbar ein treuer Anhänger der deutsch-russischen Zusammenarbeit. In diesem seinem Ziel geht er offensichtlich weiter als wir hier oder jedenfalls ich. Durch die ganze Pressegehtnoch dieNachricht von unserem wenig schönenErlebnis in derSprechstunde beim armen Dr. Skutsch. In vielen Zeitungen wird - mir unangenehm - fast über Gebühr mein Lob gesungen, während doch meine Frau auch ihre sehr großen Verdienste hatte. Dem guten Doktor soll es leidlich gehen. Ich habe heute meinen schwarzen Rock der Versicherungsgesellschaft übergeben, da auch er Brandlöcher davongetragen hat. Vielleicht bekomme ich $30 \mathrm{Mk}$ dafür.

Heute abend halten wir uns ganz ruhig und gemütlich zu Hause auf. Ich habe einen kräftigen leckeren Punsch gebraut, mit dem wir auf das neue Jahr anstoßen. Jetzt - um 10 Uhr abends - sitze ich allein hier in meinem Amtszimmer und schreibe diese Zeilen nieder. Morgen früh ist die übliche Neujahrs-Gratulation beim Herrn Reichspräsidenten. Auf Wiedersehen, altes Jahr 1930. Ich danke Gott, daß er unsere liebe Familie in diesem schlimmen Jahr gnädig behütet hat, und erhoffe und erbitte von ihm schon jetzt ein Gleiches für das neue Jahr 1931.

\section{Donnerstag, den 1. Januar 1931}

Noch gestern abend schrieb ich in diesem Tagebuch. Welch kurze Spanne und doch welch scharfe Zäsur, gestern noch „1930" und jetzt schon das neue Jahr, dem

214 Leo Chintschuk, geb. 1868, seit dem Studium in der russischen revolutionären Arbeiterbewegung tätig, 1917 Vorsitzender des Moskauer Sowjets, danach in verschiedenen hohen Staatsstellungen, 1930 Botschafter der USSR in Berlin. 